\title{
Health and Taxes: Hospitals, Community Health and the IRS
}

\author{
Mary Crossley ${ }^{*}$
}

\begin{abstract}
:
The Affordable Care Act created new conditions of federal tax exemption for nonprofit hospitals, including a requirement that hospitals conduct a community health needs assessment (CHNA) every three years to identify significant health needs in their communities and then develop and implement a strategy responding to those needs. As a result, hospitals must now do more than provide charity care to their patients in exchange for the benefits of tax exemption. The CHNA requirement has the potential both to prompt a radical change in hospitals' relationship to their communities and to enlist hospitals as meaningful contributors to community health improvement initiatives. Final regulations issued in December 2014 clarify hospitals' obligations under the CHNA requirement, but could do more to facilitate hospitals' engagement in collaborative community health projects. The Internal Revenue Service (IRS) has a rich opportunity, while hospitals are still learning to conduct CHNAs, to develop guidance establishing clear but flexible expectations for how providers should assess and address community needs. This Article urges the IRS to seize that opportunity by refining its regulatory framework for the CHNA requirement. Specifically, the IRS should more robustly promote transparency, accountability, community engagement, and collaboration while simultaneously leaving hospitals a good degree of flexibility. By promoting alignment between hospitals' regulatory compliance activities and broader community health improvement initiatives, the IRS could play a meaningful role in efforts to reorient our system towards promoting health and not simply treating illness.
\end{abstract}

* Professor, University of Pittsburgh School of Law. This Article originated in a project completed for the San Francisco Department of Public Health, supported by the Robert Wood Johnson Foundation through its Public Health Law Scholar-in-Residence Program. I thank Peter Jacobson, Wendy Parmet, Sara Rosenbaum, and Lu-in Wang for their helpful comments. My thanks also go to Stephen Matvey and Jessica Ton for their research assistance. All errors are my own. 


\section{TABLE OF CONTENTS}

TABLE OF CONTENTS............................................................................................ 52

INTRODUCTION ................................................................................................ 54

I. Hospital TAX EXemption AND COMMUnity OBLIGATION....................... 60

A. THE Hollow COMMUNITY BENEFIT STANDARD...................................... 61

B. Schedule H: What Data Reveals About Community Benefit......... 62

C. THE ACA Changes HospitalS' Obligations ......................................... 65

II. A REgUlatory FrameWORK FOR IMPROVING COMMUNITY HEALTH.. 66

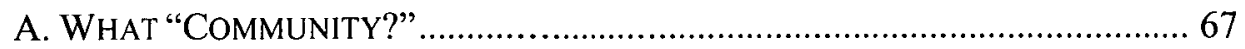

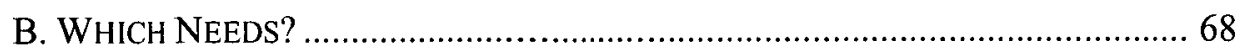

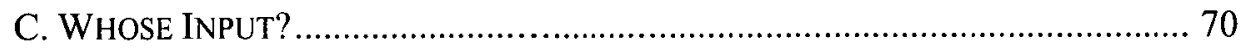

1. OPPORTUNITIES FOR COLLABORATION ………………........................ 71

D. TRANSPARENCY AND ACCOUNTABILITY .................................................. 72

E. A LINGERING QUESTION: COMMUNITY BENEFIT AND COMMUNITY HEALTH

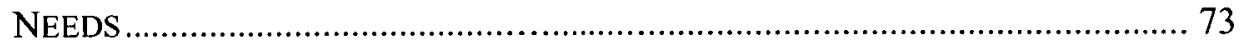

1. DOES $\S 501(R)$ COMPLIANCE FULLY SATISFY THE COMMUNITY BENEFIT

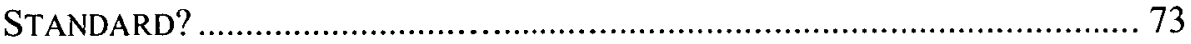

2. WHEN WILL "COMMUNITY BUILDING ACTIVITIES" COUNT AS

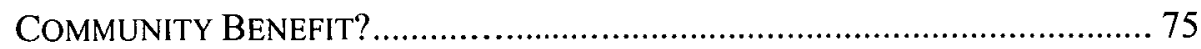

III. Hospitals and Population Health: EMbracing CONVERgenCe? 76

A. ALIGNMENT WITH THE ACA's BROAD GOALS........................................... 76

B. Convergence and Alignment with Public Health Objectives ...... 77

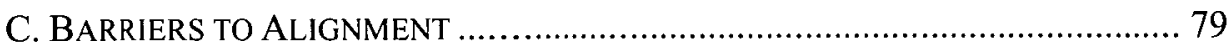

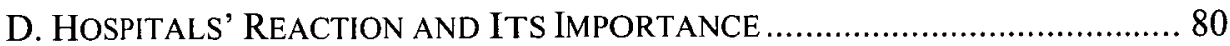

E. HoSPITALS' ATtENTION TO POPULATION HEALTH ...................................... 83

1. AdVICE FROM tHE AMERICAN HoSPITAL ASSOCIATION ..........................8 83

2. Hospitals Pursuing Population Health: SOME EXamPLES............. 85

IV. THE OPPORTUNITY GOING FORWARD....................................................... 89

A. THE IRS AS HEALTH Policy MAKER ...................................................... 89

B. FouR VALUES To PROMOTE ................................................................. 92 


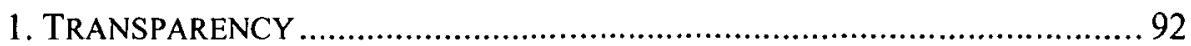

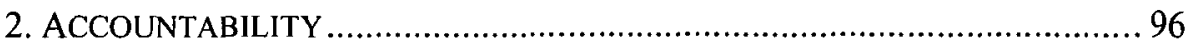

3. COMMUNITY ENGAGEMENT ..................................................... 100

4. Collaboration: Where It All Comes Together ....................... 103

C. FROM WHAT TO HoW ............................................................ 107

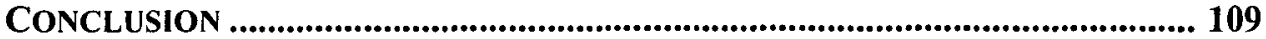




\section{INTRODUCTION}

Nothing is certain except death and taxes, it has been said, an adage suggesting that the Grim Reaper and the Internal Revenue Service (IRS) are similarly inevitable and dreadful. A provision of the Affordable Care Act ${ }^{1}$ (ACA), however, gives the IRS an opportunity to adopt health-rather than death-as its new sidekick. Specifically, the health reform law charges the IRS with implementing a provision requiring tax-exempt hospitals to assess the health needs of the communities they serve and to respond to the needs they find. How the IRS interprets and implements this statutory requirement will influence whether the steps hospitals take to satisfy this new condition of federal tax exemption contribute to improving the health of their communities, or whether hospitals' compliance efforts do little more than consume significant time and resources simply to preserve a tax advantage.

Nearly five years after the ACA's passage, the IRS promulgated final regulations on the Community Health Needs Assessment (CHNA) requirement on December 29, 2014. ${ }^{2}$ These regulations make important strides in guiding hospitals towards meaningful contributions to community health, but leave some questions unanswered. This Article will examine the CHNA requirement as the latest chapter in an ongoing saga regarding hospital tax-exemption standards and recommend values the IRS should focus on as it continues to guide hospitals. By promoting transparency, accountability, community engagement, and collaboration in its implementation of the CHNA requirement, the IRS should encourage hospitals to play a more meaningful role in improving the health of communities nationwide.

On one hand, the story of hospital tax exemption presents a cautionary tale for policymakers and fiscal monitors. The annual value of federal tax exemption for hospitals was estimated at over six billion dollars more than a decade ago, ${ }^{3}$ and a recent estimate placed the value of the federal exemption at thirteen billion dollars. ${ }^{4}$ It remains unclear exactly what public benefit justifies forgoing such

1 Patient Protection and Affordable Care Act, Pub. L. No. 111-148, 124 Stat. 119 (2010) [hereinafter ACA], amended by Health Care and Education Reconciliation Act, Pub. L. No. $111-152,124$ Stat. 1029 (2010) (codified as amended in scattered sections of 26 and 42 U.S.C.).

2 Additional Requirements for Charitable Hospitals, 79 Fed. Reg. 78,954 (Dec. 31, 2014) (to be codified at 26 C.F.R. pts. 1, 53,602).

3 Cong. Budget Office, Nonprofit Hospitals and the Provision of Community $\begin{array}{llllll}\text { BENEFITS } & 5 & (2006) & \text { [hereinafter } & \text { CBO } & \text { REPORT], }\end{array}$ www.cbo.gov/sites/default/files/cbofiles/ftpdocs/76xx/doc7695/12-06-nonprofit.pdf.

4 Sara Rosenbaum et al., The Value of the Nonprofit Hospital Tax Exemption Was $\$ 24.6$ Billion in 2011, 34 HEALTH AFF. 1225, 1228 (2015) (reporting $\$ 24.6$ billion as the combined value of federal state and local tax exemptions). 
significant tax revenue from hospitals, some (but not all) of which enjoy hefty operating incomes and margins. ${ }^{5}$ On the other hand, exempting from taxation institutions that play a meaningful role in meeting community needs may be a sound investment, especially when some (but not all) hospitals face financial stresses resulting in part from an increasingly competitive health services sector ${ }^{6}$ and hospitals' location in underserved communities. Available data support each of these perspectives, but the paucity of data regarding hospital behavior and public benefit itself has figured centrally in the debate over hospital tax exemption. ${ }^{7}$

Although the IRS has used a "community benefit" standard for hospital tax exemption for nearly fifty years, it has not employed quantitative measures or concrete directives to establish benchmarks for exemption. ${ }^{8}$ In that time period, IRS revocations of hospitals' exempt status for failure to provide community benefit were virtually unheard of. ${ }^{9}$ Debates over hospital tax exemption have erupted periodically, but only in the past decade has the IRS begun to require more specific reports from hospitals on what community benefit they actually provide. $^{10}$ The picture emerging from these reports confirmed the conventional

5 See, e.g., Kris B. Mamula, UPMC Increases Revenue, Margin in Tough Environment, PiTT. Bus. J. (Aug. 21, 2014), http://www.bizjournals.com/pittsburgh/news/2014/08/21/upmcincreases-revenue-margin-in-tough-environment.html (reporting a $\$ 190$ million operating income for the University of Pittsburgh's health system).

6 See Alexa Ura, Texas Hospitals Say They've Lost Insured Patients to Urgent Care, N.Y. TIMES (Aug. 28, 2014), http://www.nytimes.com/2014/08/29/us/texas-hospitals-saytheyve-lost-insured-patients-to-urgent-care.html.

7 Cf. Susannah Camic Tahk, Tax-Exempt Hospitals and Their Communities, 6 Colum. J. TAX L. 33, 35 (2014) (characterizing the tax-exempt hospital sector as a "virtual black box").

8 See infra Section II.A.

9 Cf. Mark C. Westenberger, Tax-Exempt Hospitals and the Community Benefit Standard: A Flawed Standard and a Way Forward, 17 Fla. TAX REV. 407, 409 (2015) (characterizing the community benefit standard as "effectively creat[ing] a per se exemption for all nonprofit hospitals"). Some states, by contrast, have been more vigorous in enforcing their own tax exemption standards for hospitals. Illinois, in particular, has actively sought to revoke exemptions of hospitals that it asserted were not providing sufficient charity care. See Bruce Japsen, Tax Man Cometh for Hospitals That Flout Charity Care Mission, ForBes (Apr. 20, 2012), http://www.forbes.com/sites/brucejapsen/2012/04/30/tax-man-cometh-forhospitals-that-flout-charity-care-mission.

10 Internal Revenue Serv., Dep't of the Treasury, OMB No. 1545-0047, Schedule H (Form 990), Hospitals (2010) [hereinafter Schedule H], http://www.irs.gov/pub/irspdf/f990sh.pdf. According to 2013 data provided by the American Hospital Association, $58 \%$ of community hospitals have not-for-profit corporate status. See Fast Facts on U.S. Hospitals, AM. HosP. Ass'N, http://www.aha.org/research/rc/stat-studies/fast-facts.shtml (last visited Dec. 2, 2015) (also reporting that for-profit hospitals account for $21 \%$ and state or local government owned hospitals account for $20 \%$ of the total). It is these nonprofit hospitals that can achieve tax-exempt status under $\S 501(\mathrm{c})(3)$ of the I.R.C. and are thus subject to the 
wisdom in health policy circles: nonprofit hospitals' reported community benefit expenditures most often involved charity care, i.e., care for patients unable to pay in full for the hospitals' services, or offsets for claimed losses from treating Medicaid patients." Thus, hospitals' actions to satisfy the community benefit standard most often benefited individual members of the public, and the benefit to the community lay in the aggregation of those individual benefits.

The ACA changed the tax-exemption landscape for hospitals, imposing additional conditions of tax-exempt status specific to hospitals. Some affect how hospitals interact with individual patients who may be unable to pay for services, but one directs hospitals to pay attention to the health needs of their communities. The new $\S 501(\mathrm{r})$ of the Internal Revenue Code (I.R.C.) requires tax-exempt hospitals to conduct a CHNA at least once every three years, to make a report of that assessment publicly available, and to adopt a plan for responding to the needs identified. ${ }^{12}$ Community health assessments are standard fare for health departments. A CHNA typically involves the collection and analysis of quantitative and qualitative data in order to understand the health issues a specific community faces and to inform strategies for addressing those issues. ${ }^{13}$ Most hospitals in the United States had probably never conducted a CHNA prior to the ACA's requirement. ${ }^{14}$ Thus, these hospitals face a new and largely unfamiliar condition for federal tax exemption.

One might view the new CHNA requirement as simply an attempt to ensure that hospitals provide some real community benefit as the quid pro quo for the tax benefits they receive. Indeed, conducting a CHNA and reporting on it do

community benefit requirement and to the new requirements under $\S 501(\mathrm{r})$.

11 See Rosenbaum et al., supra note 4, at 1226; Gary J. Young et al., Provision of Community Benefits by Tax-Exempt U.S. Hospitals, 368 NEW ENG. J. MED. 1519 (2013); infra Section I.B for further discussion.

1226 U.S.C. $\$ 501(\mathrm{r})(3)(2012)$.

13 See Acronyms and Glossary of Terms Version 1.0, Pub. Health ACCReditation Bd. 8 (2011), http://www.phaboard.org/wp-content/uploads/PHAB-Acronyms-and-Glossary-ofTerms-Version-1.0.pdf (defining community health assessment as "a systematic examination of the health status indicators for a given population that is used to identify key problems and assets in a community. The ultimate goal of a community health assessment is to develop strategies to address the community's health needs and identified issues. A variety of tools and processes may be used to conduct a community health assessment; the essential ingredients are community engagement and collaborative participation").

14 Prior to the ACA, eleven states required some form of community health assessment as a condition of state hospital tax exemption. Gayle D. Nelson et al., Hospital Community Benefits After the ACA: Policy Implications of the State Law Landscape, HILLTOP INST. (2013), http://www.hilltopinstitute.org/publications/HospitalCommunityBenefitsAfterTheACAPolicyImplicationsIssueBrief7-Sept2013.pdf. 
demand tangible new actions from hospitals. The CHNA requirement, however, has the potential to prompt a more radical change in hospitals' role in promoting health and in their relationship to their communities. The requirement encourages hospitals to become involved in not only the treatment, but also the prevention of ill health. It directs a hospital to shift its gaze outward, to engage with its surrounding community, and to consider how the hospital might play a role in meeting the health needs of that community - that group of people-and not simply the medical needs of individual community residents. In so doing, the CHNA requirement is part of a broader emphasis on public health and prevention in the $\mathrm{ACA}^{15}$ that, however modestly, moves the U.S. healthcare system and public health system toward integration. ${ }^{16}$

Will the CHNA requirement succeed in prompting meaningful hospital engagement with and response to communities' needs? For some hospitals, "community outreach" has been a euphemism for marketing hospital services to prospective patients. ${ }^{17}$ Expecting them to play a role in getting and keeping community members healthy — and out of the hospital—is truly asking something new of most hospitals. Some commentators celebrate the CHNA requirement as a golden opportunity to include hospitals in community partnerships seeking to address health needs ranging from improving access to screenings or prenatal care, to addressing social determinants of health and health disparities. Under this conception, the CHNA requirement thus becomes a key way to involve hospitals in prevention-oriented strategies for containing health spending nationally. ${ }^{18}$ Others are skeptical. ${ }^{19}$ As long as hospitals' own financial health depends on

15 While the ACA is best known for its steps to achieve near-universal insurance coverage for Americans, the mammoth health reform bill also included numerous provisions seeking to shift more public and private resources towards promoting wellness, rather than simply responding to illness. See infra text accompanying note 106. This shift in emphasis embodies the "Triple Aim" model of health policy, which includes "population health" as one of its three aims. See Donald M. Berwick et al., The Triple Aim: Care, Health, and Cost, 27 HEALTH AFF. 759, 764 (2008).

16 See Lawrence O. Gostin et al., Restoring Health to Health Reform: Integrating Medicine and Public Health To Advance the Population's Wellbeing, 159 U. PA. L. REV. 1777 (2011); see also Stephen M. Shortell, Bridging the Divide Between Health and Health Care, 309 JAMA 1121, 1121 (2013) ("[C]onsensus is developing that truly controlling health care costs and improving the overall health of the American people will require a much closer partnership, permeable boundaries, and increased interdependence among the health care delivery system, the public health sector, and the community development and social service sectors."); cf. David A. Asch \& Kevin G. Volpp, What Business Are We in? The Emergence of Health as the Business of Health Care, 367 NEW ENG. J. MED. 888, 888 (2012) ("Whereas doctors and hospitals focus on producing health care, what people really want is health.").

17 See infra note 194 and accompanying text.

18 See infra Section IV.B.

19 See Zachary J. Buxton, Community Benefit 501(R)edux: An Analysis of the Patient Protection and Affordable Care Act's Limitations Under Community Benefit Reform, 7 ST. 
treating patients in the hospital, they reason, rarely enforced tax-exemption standards will produce little meaningful change in hospitals' behavior.

This Article proceeds from the premise that increasing hospitals' participation in collaborative efforts to improve community health could help address the persistent health issues and disparities plaguing many communities. ${ }^{20}$ Increasingly, leaders in both medicine and public health are recognizing the importance of connecting clinical care providers to population health approaches as a strategy for controlling costs while improving health outcomes. ${ }^{21}$ Whether the new CHNA requirement will cause hospitals to engage meaningfully in community health projects will depend on many factors, including how reimbursement reforms and other non-tax-related incentives shape hospital behavior, ${ }^{22}$ as well as how the IRS interprets, implements, and enforces the ACA's requirement. This Article examines how the IRS could use its regulatory authority to encourage hospitals to play significant roles in community health transformation efforts, thus aligning their vision and energy with that of community partners.

One thing is certain: the CHNA requirement has captured hospitals' attention. Some hospitals have tapped into expertise from consultants and public health academics for help in conducting their first CHNA, while others have muddled through the requirements on their own. Public health researchers are studying all those efforts and considering how hospitals' community health assessments and partnerships might be made more efficient and effective. ${ }^{23}$ The IRS has a rich opportunity, while hospitals are on this learning curve and before they develop entrenched practices, to develop guidance establishing clear but flexible expectations for how hospitals should assess and address community needs.

LOUIS. U. J. HEALTH L. \& POL'Y 449, 450 (2014) (characterizing the ACA's new requirements for tax-exempt hospitals as "nothing more than superficial misdirection from community benefit's existing issues" and the CHNA requirement as "wholly unworkable in practice"); see also infra Section IV.C (addressing potential barriers to hospital and public health collaborations).

20 This premise currently lacks solid empirical evidence and thus is debatable, but on balance it seems sensible. See infra Section IV.B (discussing the value of hospitals' participation in community health improvement projects).

21 See, e.g., Thomas D. Sequist \& Elsie M. Taveras, Clinic-Community Linkages for High-Value Care, 371 NEw ENG. J. MED. 2148, 2148 (2014) ("One essential strategy for improving population health is linking the delivery system, the community, and the patient in an integrated effort.").

22 For example, hospitals that are required to provide a certain quantity of charity care as a condition of state and local tax exemption may be disinclined to make significant additional investments in community health initiatives.

23 See infra text accompanying notes 167-171. 
This Article urges the IRS to seize that opportunity by refining its regulatory framework for the CHNA requirement in order to more robustly promote transparency, accountability, community engagement, and collaboration, ${ }^{24}$ while simultaneously leaving hospitals some degree of flexibility. The IRS must push hospitals to expand their sense of responsibility to their communities, without unduly burdening them. Hospitals can make distinctive contributions to community health initiatives even as their core activity remains caring for patients. Spurring hospitals' active participation in community health improvement via regulatory guidance will not be simple, but the prize for success may be significant. In addition to advancing the health of communities, independent value may lie in getting hospitals "on board" as members of the team tackling community health problems. Accomplishing this would be a significant step toward a convergence of the healthcare and public health systems, seen by a growing number of policymakers and academics as a key to improving health outcomes in the United States. ${ }^{25}$

Part I briefly describes the historical evolution of standards for hospital tax exemption, while examining growing dissatisfaction with the community benefit standard and the ACA's inclusion of new requirements for tax-exempt hospitals. Part II describes the final IRS regulations issued in December 2014 and assesses how they measure up in terms of promoting transparency, accountability, community engagement, and collaboration. Part III shows how the CHNA requirement presents an opening to boost hospital participation in collaborative community health initiatives and describes how some hospitals are already shifting their attention to community health needs and pursuing innovative approaches to address those needs. Part IV discusses how the IRS could encourage hospitals to reorient their community benefit investments and participate in collaborative efforts to effect community health improvement. By using its regulatory authority to promote alignment between hospitals' regulatory compliance activities and coinciding community health improvement initiatives, the IRS could itself play a meaningful role in the broader effort to reorient our system towards promoting health and not simply treating illness.

24 Other commentators have identified similar lists of values for guiding hospitals' involvement in community health efforts. See, e.g., Sara Rosenbaum, Principles To Consider for the Implementation of a Community Health Needs Assessment Process, GEO. Wash. U. SCH. Pub. Health \& Health SeRvs. (2013),

http://nnphi.org/CMSuploads/PrinciplesToConsiderForTheImplementationOfACHNAProcess _GWU_20130604.pdf; Stephen M. Shortell et al., The Contribution of Hospitals and Health Care Systems to Community Health, 30 AnN. Rev. Pub. Health 373, 380-81 (2009).

25 See Thomas R. Friedan, The Future of Public Health, 373 New ENG. J. MED. 1748, 1753 (2015) (stating, as Director of the Centers for Disease Control and Prevention, that " $[\mathrm{b}] \mathrm{y}$ working more closely together, clinical medicine and public health can help each other improve health maximally"); Gostin et al., supra note 16, at 1791-93. 


\section{HOSPITAL TAX EXEMPTION AND COMMUNITY OBLIGATION}

The ACA's requirement that tax-exempt hospitals conduct CHNAs, while novel for most hospitals, supplements the longstanding community benefit standard. Consequently, this Article's discussion of hospitals' new responsibilities requires a basic understanding of how the community benefit standard has evolved.

I.R.C. $\S 501(\mathrm{c})(3)$ enables organizations that are "organized and operated exclusively for religious, charitable, scientific ... or educational purposes" to achieve exemption from federal income tax obligations. ${ }^{26}$ A substantial majority of U.S. hospitals are tax-exempt under $\S 501(\mathrm{c})(3),{ }^{27}$ and the financial value of tax exemption (in the form of forgone tax payments, the value of tax-exempt bond financing, and the deductibility of contributions) is enormous. The Congressional Budget Office (CBO) estimated that in 2002 the annual value of the federal tax exemption for nonprofit hospitals was $\$ 6.1$ billion. ${ }^{28} \mathrm{~A}$ more recent estimate, replicating the CBO's methodology, placed the figure at $\$ 13.0$ billion. ${ }^{29}$ Including the value of state and local exemptions as well increases the estimate to $\$ 24.6$ billion. $^{30}$

The question of how hospitals-which typically charge patients (or their insurers) for the care provided and often compete fiercely with their rivals-are understood as having a "charitable" purpose under federal law has evolved over time. Policymakers and scholars have advanced various rationales, including the views that nonprofit hospitals surpass for-profit hospitals in providing collective goods (for example, providing unprofitable services) ${ }^{31}$ and that, by providing charity care, hospitals relieve government of a burden it would otherwise bear. ${ }^{32}$

2626 U.S.C. $\$ 501(c)(3)(2012)$.

27 U.S. GOV'T ACCOUNTABILITY OFFICE, GAO-08-880, NONPROFIT Hospitals: VARIATION IN STANDARDS AND GUIDANCE LIMITS COMPARISON OF HOW HOSPITALS MEET COMmunity BENEFIT ReQuiREMENTS 8 (2008) [hereinafter GAO RePORT]. Beyond the exemption from paying corporate income taxes, this status also permits hospitals to accept charitable contributions that are tax deductible by the donor and may qualify them to issue tax-exempt bonds to finance capital projects. Id. at 12 .

28 See CBO REPORT, supra note 3.

29 See Rosenbaum et al., supra note 4, at 1227.

30 Id. at 1228.

31 CBO REPORT, supra note 3 , at 4 (suggesting that providing uncompensated care to indigent individuals might also be viewed as a collective good because it may satisfy community members' "compassionate impulses" and prevent the spread of disease); see Jill R. Horwitz, Why We Need the Independent Sector: The Behavior, Law, and Ethics of Not-forProfit Hospitals, 50 UCLA L. REv. 1345, 1347 (2003).

32 GAO REPORT, supra note 27 , at 10 ("This exemption is based on the principle that the government's loss of tax revenue is offset by its relief from financial burdens that it would otherwise have to meet with appropriations from public funds."). 
These rationales are often framed in terms of a quid pro quo: in exchange for substantial tax relief, hospitals supply something valuable to the government or their community. ${ }^{33}$ Others, however, argue the exemption is unjustified, asserting that the government has not reliably extracted from nonprofit hospitals the benefits that could in theory justify exemption. ${ }^{34}$ Empirical evidence of hospital behavior was for decades quite thin, making it difficult to evaluate the competing claims.

\section{A. The Hollow Community Benefit Standard}

Changes in the healthcare financing and delivery system since the middle of the twentieth century have shaped the evolution of the standard for hospital tax exemption. In 1956 the IRS announced that, to be considered "charitable," a hospital must operate "to the extent of its financial ability for those not able to pay for the services rendered and not exclusively for those who are able and expected to pay." ${ }^{\prime 35}$ The IRS never quantified what level of charity care this "financial ability" standard demanded, however. The creation of Medicare and Medicaid in 1965 prompted concern that these programs would so diminish the need for charity care that hospitals would no longer be able to maintain their taxexempt status. ${ }^{36}$ As a result, in 1969 the IRS established the "community benefit" standard ${ }^{37}$ to replace the "financial ability" standard. Even if a hospital did not provide significant charity care, the community benefit standard found a charitable purpose in the hospital's provision of healthcare services that benefited the community generally. A Revenue Ruling setting out five factors ${ }^{38}$ the IRS considered in granting tax exemption had been (with only minor adjustments ${ }^{39}$ )

33 See Lloyd H. Mayer, The "Independent" Sector: Fee-for-Service Charity and the Limits of Autonomy, 65 VAND. L. REV. 49, 64-69 (2012) (discussing and critiquing theories justifying exemption and identifying the important role of public benefit in explaining charities' exempt status).

34 See M. Gregg Bloche, Health Policy Below the Waterline: Medical Care and the Charitable Exemption, 80 MINN. L. REv. 299, $352-53$ (1995); John D. Colombo, The Failure of Community Benefit, 15 HEALTH MATRIX 29, 51 (2005).

35 Rev. Rul. 56-185, 1956-1 C.B. 202.

36 Daniel M. Fox \& Daniel C. Schaffer, Tax Administration as Health Policy: Hospitals, the Internal Revenue Service, and the Courts, 16 J. HEALTH POL. POL'Y \& L. 251 (1991).

37 Rev. Rul. 69-545, 1969-2 C.B. 117.

$38 \mathrm{Id}$. These factors include operating an open emergency room, participating in public insurance programs, and having an independent governing board. The 1969 Revenue Ruling also indicates that the IRS will consider all the facts and circumstances regarding each hospital and that neither the absence of a listed factor or the presence of markers of community benefit will necessarily be dispositive.

39 In 1983, the IRS adjusted the standard to provide that the requirement of an open emergency room might not always apply. Rev. Rul. 83-157, 1983-2 C.B. 94. 
the sole direction to hospitals regarding their obligations as tax-exempt entities. Practically speaking, the IRS typically did not scrutinize a tax-exempt hospital's ongoing operations to assess, much less quantify, what benefits its community actually received.

Thus, for four decades, the community benefit standard let hospitals enjoy the benefits of federal tax exemption without definite accountability. By the turn of the century, however, some members of Congress and federal regulators began arguing for more rigorous and quantifiable community benefit standards. ${ }^{40}$ Reports from the CBO and the Government Accountability Office (GAO) highlighted the lack of consensus on how to define or measure community benefit ${ }^{41}$ and discretion was left to individual hospitals in these matters. ${ }^{42}$ Media exposés in the early 2000 s that reported on decidedly uncharitable behavior by tax-exempt hospitals, including charging uninsured patients rates that far exceeded those charged to insured patients and employing heavy-handed debt collection practices against patients unable to pay the hospitals' charges, caught Congress's and the public's attention. ${ }^{43}$

\section{B. Schedule H: What Data Reveals About Community Benefit}

The increased public scrutiny captured the hospital industry's attention. In 2006, the American Hospital Association (AHA) issued guidelines suggesting how hospitals might account for their community benefits by emphasizing the value of charity care and uncompensated care. ${ }^{44}$ The same year, the IRS undertook its "Hospital Compliance Project," sending questionnaires to more than five hundred nonprofit hospitals to learn how they provided a community benefit. ${ }^{45}$ Based on the results, in 2007 the IRS took its first step towards increased accountability and transparency, introducing a mandatory reporting

40 See, e.g., GAO REPORT, supra note 27, at 4 (describing Senator Grassley's request for "feedback on whether hospitals should be required to devote a minimum percentage of patient operating expenses or revenues (whichever is greater) to charity care in order to continue to qualify for federal tax exemption").

41 CBO REPORT, supra note 3, at 1.

42 GAO REPORT, supra note 27 , at 7.

43 See Erin C. Fuse Brown, Fair Hospital Prices Are Not Charity: Decoupling Hospital Pricing and Collection Rules from Tax Status, 53 U. LouISVILLE L. REV. (forthcoming 2016) (manuscript at 19-20), http://papers.ssrn.com/sol3/papers.cfm?abstract_id=2451435 (describing "a flurry of hearings and inquiry in the early-mid 2000s" and "a wave of over sixty class action suits").

44 AHA Guidance on Reporting of Community Benefit, AM. HosP. Ass'N (2006), www.aha.org/content/00-10/061113cbreporting.pdf.

45 IRS Exempt Organizations Hospital Study Executive Summary of Final Report, INTERNAL REVENUE SERV. (2009) [hereinafter IRS Hospital Study], http://www.irs.gov/pub/irs-tege/execsum_hospprojrept.pdf. 
schedule specifically for hospitals (Schedule H) as part of the Form 990 annual informational return for all tax-exempt organizations.

Part I of Schedule $\mathrm{H}$ directed hospitals to detail their expenditures for "Financial Assistance and Certain Other Community Benefits" and indicated several categories of relevant expenditures. These categories included financial assistance, unreimbursed costs from means-tested government programs, health professions education, research, cash and in-kind contributions, as well as a category labeled "community health improvement services and community benefit activities." "46 Part II directed hospitals to report separately their participation in "community building activities." Several examples from Schedule H's list of reportable "community building activities" include "physical improvements and housing," "economic development," and "community support. ${ }^{.47}$ As discussed below, by creating separate reporting categories for "community health improvement services" and "community building activities" and designating only the former as a type of community benefit expenditures, the IRS may have sown confusion that now impedes hospitals' embrace of activities addressing broad social determinants of health. ${ }^{48}$

As the first decade of the twenty-first century drew to a close, the IRS appeared ready to impose some accountability on hospitals. Schedule H's required accounting for community benefit expenditures supplied a novel opportunity to compare hospitals' practices on an "apples to apples" basis. However, the first such major comparison published confirmed the conventional wisdom that hospitals sought to satisfy the community benefit standard primarily by providing care to indigent or uninsured patients who could not pay for their care. ${ }^{49}$ A study published in the New England Journal of Medicine found that in

46 A worksheet fleshes out this category's scope. Foreshadowing the ACA's new requirement, the instructions indicate that these include activities associated with community health needs assessments and activities or programs justified by an established community need. See Schedule H, supra note 10, at Worksheet 4.

47 See id.

48 For a definition of social determinants of health, see infra note 79.

49 See Daniel B. Rubin et al., Evaluating Hospitals' Provision of Community Benefit: An Argument for an Outcome-Based Approach to Nonprofit Hospital Tax Exemption, 103 AM. J. PuB. HealTH 612, 613 (2013) ("[M]any nonprofit hospital leaders still consider community benefit to be largely synonymous with charity care ...."); cf. CBO REPORT, supra note 3, at 1 (adopting, for purpose of analysis comparing community benefits provided by for-profit and non-profit hospitals, a definition of community benefit that includes "the provision of uncompensated care, the provision of services to Medicaid patients, and the provision of certain specialized services that have been identified as generally unprofitable"); INTERNAL Revenue Serv., iRS Exempt Organizations (TE/GE) Hospital Complance Project: FINAL REPORT 4 (2009), https://www.irs.gov/pub/irs-tege/frepthospproj.pdf (finding that "[u]ncompensated care was the largest reported community benefit expenditure overall and across all demographics" in a recent comprehensive survey). 
fiscal year 2009, tax-exempt hospitals spent an average of $7.5 \%$ of their operating expenses on community benefits. ${ }^{50}$ Of these expenditures, more than $85 \%$ were related to providing care to individual patients. More than half of that category (or $45.3 \%$ of hospitals' reported community benefit expenditures) reflected hospitals' costs for treating patients covered by means-tested government programs (mostly Medicaid) to the extent that those costs were not fully covered by government reimbursement. In comparison, charity care accounted for $25.3 \%$ of community benefit expenditures, and subsidized health services accounted for $14.7 \%{ }^{51}$ By contrast, a mere $5.3 \%$ of the hospitals' community benefit expenditures (or $0.4 \%$ of total hospital expenditures) went to direct community health improvement projects. An IRS report to Congress in 2015 contained similar breakdowns of the categories of spending, with $32 \%$ of community benefit spending in 2011 going to offset losses from government programs, $24 \%$ devoted to providing financial assistance to low-income patients, and $4 \%$ to community health improvement. ${ }^{52}$

These figures lend heft to critiques of the effectiveness of the pre-ACA community benefit standard in producing meaningful benefits for communities. A common refrain of skeptics is that any benefits that tax-exempt hospitals provide to their communities and the people in them are small in comparison to the value that hospitals receive from tax exemption. As the types of expenditures that hospitals called "community benefit" expanded, the benefits actually flowing to the community as the quid pro quo for tax exemption shrank. For example, in 2013 the AHA published a study of hospital community benefit reporting that referred to both bad debt (uncollectible billings) and the amount by which a hospital's total allowable Medicare costs exceeds its Medicare revenues as community benefit expenditures, even though these expenses are simply costs of doing business for any hospital. ${ }^{53}$ Recent revelations regarding the apparent

50 See Young et al., supra note 11 , at 1519.

$51 \mathrm{Id}$. at $1523 \mathrm{fig} .1$. It bears emphasizing that the study found "considerable variation" among hospitals in how much they spent on community benefit, with hospitals in the top spending decile reporting community benefit expenditures equaling $20.1 \%$, on average, of their total expenditures, while hospitals in the bottom decile reported an average of $1.1 \%$. Id. at 1522. A subsequent study analyzing data from the Schedule Hs filed by all tax-exempt hospitals in 2012 also found significant variation in the categorization of hospitals' reported expenditures. See Tahk, supra note 7. This study compared the expenditures that hospitals reported as "community benefits" on Schedule H with expenditures reported in the section of Schedule $\mathrm{H}$ for "community building" activities. It found that hospitals that devote more resources to community benefit as traditionally understood tend to be large hospitals in densely populated communities with many residents living just above the poverty line, while hospitals that spend more on community building tend to be located in communities whose residents are more likely to be privately insured. $I d$. at 36 .

52 See Rosenbaum et al., supra note 4, at 1226 (describing the IRS's 2015 report).

53 See Sara Rosenbaum, Hospital Community Benefit Expenditures: Looking Behind the 
arbitrariness of inflated hospital charges ${ }^{54}$ call into question the consistency and legitimacy of how hospitals calculate their Medicaid shortfall, which (unlike bad debt and Medicare shortfall) is a permitted category of community benefit spending on Schedule H. If we also take into account research indicating that the behavior of non-profit hospitals does not differ meaningfully from that of forprofit hospitals in terms of social benefit provided, ${ }^{55}$ skepticism as to whether the community benefit standard for tax exemption has produced real, quantifiable benefits to communities seems well justified.

\section{The ACA Changes Hospitals' Obligations}

Against this backdrop of mounting criticism of the community benefit standard and more data about hospitals' community benefit accounting, the ACA's enactment in 2010 ushered in significant changes to hospital tax exemption by creating additional conditions for hospitals, codified in a new I.R.C. $\S 501(\mathrm{r}){ }^{56}$ This provision of the ACA was pushed by Senator Charles Grassley, a vocal critic of hospitals' lack of accountability for community benefits and the egregious ways some hospitals treated poor patients. ${ }^{57}$ Responding to the latter concern, several new requirements address how hospitals interact with their patients around matters of financial assistance, charges for services, and debt collection. ${ }^{58}$ However, these requirements stop short of requiring hospitals to provide any particular quantum of free care to patients unable to pay. ${ }^{59}$ The ACA's other new requirement takes a different tack, establishing the CHNA requirement as part of the quid pro quo for relieving hospitals from their federal tax liability.

Numbers, HEALTH AfF. BLOG (June 11, 2013), http://healthaffairs.org/blog/2013/06/11/hospital-community-benefit-expenditures-lookingbehind-the-numbers.

54 See Steven Brill, Bitter Pill: How Outrageous Pricing and Egregious Profits Are Destroying Our Health Care, Time, Mar. 4, 2013, at 16; Barry Meier et al., Hospital Billing Varies Wildly, Government Data Shows, N.Y. TIMES (May 8, 2013), http://www.nytimes.com/2013/05/08/business/hospital-billing-varies-wildly-us-datashows.html.

55 See Colombo, supra note 34, at 46 ("In general, independent reviews of the existing literature on the behavioral differences of nonprofit and for-profit hospitals find the studies at best inconclusive regarding whether nonprofit hospitals provide more socially-beneficial behavior in the form of better care, cheaper-but-equally-as-good care, or more charity care.").

5626 U.S.C. $\S 501(\mathrm{r})(2012)$.

57 See Brown, supra note 43 , at 20-21.

58 See id. at 4 (summarizing the new requirements).

59 See id. at 24 (noting that $\S 501(\mathrm{r})$ contains "no specific requirements for the substance of or criteria for financial assistance"). 
The statute specifies a series of steps for the CHNA requirement. First, a hospital must conduct a CHNA at least once every three years, taking into account "input from persons who represent the broad interests of the community served by the hospital facility, including those with special knowledge of or expertise in public health." ${ }^{60}$ Once it has completed the CHNA, the hospital must make a report on it "widely available to the public." 61 The hospital must then adopt an "implementation strategy to meet the community health needs identified through such assessment." ${ }^{\text {"62 }}$ By establishing this multi-step process, Congress sought to ensure that tax-exempt hospitals in fact take steps to respond to the health needs of their communities. Due to the spare statutory language, the task of filling the many gaps regarding what exactly hospitals must do to meet the new CHNA requirement fell to the Secretary of the Treasury and the IRS. ${ }^{63}$

\section{A REGULATORY FRAMEWORK FOR IMPROVING COMMUNITY HEALTH}

Developing regulations to implement the CHNA requirement was a regulatory odyssey stretching over nearly five years. It culminated on December 31, 2014 with the publication of final regulations (the "Regulations") 64 that answered, at least partially, ${ }^{65}$ many of the questions regarding hospitals'

$60 \S 501(\mathrm{r})(3)(\mathrm{B})(\mathrm{i})$.

$61 \S 501(\mathrm{r})(3)(\mathrm{B})(\mathrm{ii})$.

$62 \S 501(\mathrm{r})(3)(\mathrm{A})(\mathrm{ii})$.

$63 \S 501(r)(7)$.

64 The final regulations followed the publication of proposed regulations regarding hospitals' CHNA obligation in April 2013, 78 Fed. Reg. 20,523 (proposed Apr. 5, 2013) (to be codified at 26 C.F.R. pts. 1, 53), which followed a Preliminary Guidance issued in July 2011, Internal Revenue Bulletin: 2011-30, Notice and Request for Comments Regarding the Community Health Needs Assessment Requirements for Tax-Exempt Hospitals, INTERNAL REVENUE SERV. (July 25, 2011), http://www.irs.gov/irb/2011-30_IRB/ar08.html. The IRS also separately published proposed regulations regarding $\S 501(\mathrm{r})$ 's other requirements regarding financial assistance, billing, and collection policies. See Additional Requirements for Charitable Hospitals, 77 Fed. Reg. 38,148 (proposed June 26, 2012) (to be codified at 26 C.F.R. pt. 1). The final Regulations address all of $\S 501(r)$ 's requirements for hospitals. See Additional Requirements for Charitable Hospitals, 79 Fed. Reg. 78,954 (Dec. 31, 2014) (to be codified at 26 C.F.R. pts. 1, 53, 602).

65 Of particular note in those states that already had some kind of community health assessment requirements for hospitals prior to the ACA's enactment, the Regulations are silent on one question: will the IRS deem hospitals' compliance with analogous state law requirements to satisfy the CHNA requirements of the new $\S 501(\mathrm{r})$ ? If not, those hospitals argue, the duplicative-or, even worse, conflicting - obligations of federal and state law will be unduly burdensome. See California Hospital Association, Comment Letter on Proposed Rule Regarding Community Health Needs Assessments for Charitable Hospitals 1 (July 3, 2013), http://www.regulations.gov/contentStreamer?documentId=IRS-2013-00160038\&attachmentNumber=1\&disposition=attachment\&contentType=pdf (urging the IRS to consider "deemed status for states like California with existing state law"). Similarly, although 
CHNA obligations left open by $\S 501(r)$. The Regulations address a broad range of questions, including who is subject to the CHNA requirements, deadlines for compliance, and penalties for noncompliance. ${ }^{66}$ As a foundation for understanding the Regulations' implications for hospitals' meaningful participation in community health improvement initiatives, this Part describes how the Regulations address basic aspects of the CHNA requirement, including how hospitals should define the community whose needs are to be assessed and the kinds of needs to be catalogued. It then summarizes aspects of the Regulations relevant to expectations of transparency, accountability, community engagement, and collaboration as hospitals take on an expanded role regarding community health.

\section{A. What "Community?"}

Health services research often uses the term "catchment area" to describe a hospital's market area, or the geographic area from which it draws patients. ${ }^{67}$ Because the ACA expects hospitals to enlarge their concern beyond their actual patients, however, defining the "community" whose health needs the hospital must assess is a critically important first step. The Regulations adopt a generally permissive stance on this question, providing that a hospital "may take into account all of the relevant facts and circumstances, including the geographic area served ... . target population(s) served . . . , and principal functions (for example, focus on a particular specialty area or targeted disease). ${ }^{, 68}$ A stricter tone prevails regarding the possibility that a hospital might cherry-pick its community: "[A] hospital may not define its community to exclude medically underserved, lowincome, or minority populations who live in geographic areas from which the hospital draws its patients." "The reference to "medically underserved populations" sweeps broadly, including "populations experiencing health disparities or at risk of not receiving adequate medical care as a result of being uninsured or underinsured or due to geographic, language, financial, or other

Schedule $\mathrm{H}$ to Form 990 calls for a hospital to identify any state with which it files a community benefit report, it does not inquire specifically about health needs assessments performed pursuant to state law. Schedule H, supra note 10 .

66 See 26 C.F.R. $\S 1.501(\mathrm{r})-3(\mathrm{a})$, (d) (2015) (establishing the CHNA obligation and exceptions for certain hospital facilities); $\S 1.501(\mathrm{r})-3(\mathrm{a})(2)$ (establishing the deadline for adoption of an implementation strategy); $\S 1.501(\mathrm{r})-2$ (establishing consequences for failures to satisfy $\S 501(\mathrm{r}))$.

67 See, e.g., Stuart John Gilmour, Identification of Hospital Catchment Areas Using Clustering: An Example from the NHS, 45 HEALTH SERV. RES. 497 (2010).

$68 \S 1.501(\mathrm{r})-3(\mathrm{~b})(3)$.

$69 \mathrm{Id}$. 
barriers." ${ }^{70}$ Thus, hospitals enjoy significant flexibility in defining their communities, but cannot exclude the very populations most likely to have significant health needs. ${ }^{71}$

Another point on which the Regulations are clear is that the CHNA must be conducted at the individual hospital facility level, even for hospitals that are part of multi-hospital systems. ${ }^{72}$ By contrast, Schedule $\mathrm{H}$ requires an organization to consolidate its reporting of community benefit operations. ${ }^{73}$ Although the Regulations permit multi-facility CHNAs for hospitals that serve the same community, the general requirement that each hospital define its own community (whose needs it must assess and address) may result in investments targeting more specific needs. ${ }^{74}$

\section{B. Which Needs?}

Allaying hospitals' concerns that they might be expected to catalog exhaustively every health need existing in their communities, the Regulations clarify that hospitals must identify only the "significant health needs of the community." In doing so, a hospital can consider both the needs of its community as a whole and the needs of "particular parts of the community (such as particular neighborhoods or populations experiencing health disparities)." Once a hospital has identified significant health needs, it must prioritize them and "identify resources ... potentially available to address those health needs.","

But what counts as a "health need," and what makes it "significant?" On the first question, the final Regulations lay the groundwork for having hospitals "think big" in seeking to address root causes of poor health in their communities. ${ }^{77}$ In response to comments on the proposed regulations, the IRS

$70 \S 1.501(\mathrm{r})-3(\mathrm{~b})(5)(\mathrm{i})(\mathrm{B})$.

71 But cf. Supporting Alignment and Accountability in Community Health Improvement: The Development and Piloting of a Regional Data-Sharing System, PUB. HEALTH INST. (2014) [hereinafter Supporting Alignment and Accountability in Community Health Improvement], http://nnphi.org/CMSuploads/SupportingAlignmentAndAccountabilityInCommunityHealthIm provement.pdf (finding that hospitals failed to pay sufficient attention to disparities in their communities).

$72 \S 1.501(\mathrm{r})-3(\mathrm{a})(1)$ (establishing the CHNA for hospital facilities).

73 See Instructions for Schedule $H$ (Form 990), InTERnal Revenue Serv. (2014), https://www.irs.gov/pub/irs-pdf/i990sh.pdf.

74 Professor Sara Rosenbaum suggested this point to me.

$75 \S 1.501(\mathrm{r})-3(\mathrm{~b})(4)$.

$76 \mathrm{ld}$.

77 See, e.g., Sara Rosenbaum, Additional Requirements for Charitable Hospitals: Final Rules on Community Health Needs Assessments and Financial Assistance, HeAlth AFF. BLOG (Jan. 23, 2015), http://www.healthaffairs.org/blog/2015/01/23/AdditionalRequirements-For-charitable-Hospitals-Final-Rules-on-community-Health-Needs- 
added language embracing a broad understanding of community health needs:

[T] he health needs of a community include requisites for the improvement or maintenance of health status... These needs may include, for example, the need to address financial and other barriers to access care, to prevent illness, to ensure adequate nutrition, or to address social, behavioral, and environmental factors that influence health in a community. ${ }^{78}$

Thus, under the Regulations, social determinants of health-factors like the availability or absence of healthful foods, transportation options, living wages, and safe neighborhoods ${ }^{79}$ - are among the health needs that hospitals should consider in their CHNAs.

By contrast, the Regulations provide no guidance on a "significance" threshold, referring simply to "all of the facts and circumstances present in the community. ${ }^{, 80}$ In addition, rather than providing advice on how hospitals should prioritize the significant needs they identify, the Regulations only offer suggestions: a hospital "may use any criteria . . . including, but not limited to, the burden, scope, severity, or urgency of the health need; the estimated feasibility and effectiveness of possible interventions; the health disparities associated with the need; or the importance the community places on addressing the need." 81

The Regulations commendably embrace a broad understanding of "health needs" by encompassing social determinants of health. However, their extreme deference to a hospital's judgment in determining significance and prioritization may undercut the population health value of that broad understanding. The Regulations require hospitals to solicit input from community members and public health officials and to report on their process and findings, and this input should influence hospitals' determinations of significance and priorities. Nonetheless, the Regulations' failure to establish meaningful standards for

Assessments-and-Financial-Assistance (stating that the broad definition is a "strong signal that the CHNA process is about community health")

$78 \S 1.501(\mathrm{r})-3(\mathrm{~b})(4)$.

79 See Determinants of Health, Healthy People 2020, http://www.healthypeople.gov/2020/about/foundation-health-measures/Determinants-ofHealth (last visited Dec. 2, 2015). The Centers for Disease Control and Prevention lists social environment and physical environment, along with biology and genetics, individual behavior, and health services as primary determinants of health. Social Determinants of Health, CTRS.

DISEASE

CONTROL

\&

PREVENTION, http://www.cdc.gov/nchhstp/socialdeterminants/definitions.html (last visited Dec. 2, 2015). For scientific research regarding the impact of social determinants, see SoclaL DETERMINANTS OF HEALTH (Michael Marmot \& Richard G. Wilkinson eds., 1999).

$80 \S 1.501(\mathrm{r})-3(\mathrm{~b})(4)$.

$81 \mathrm{Id}$. 
significance and priorities could permit a hospital to identify as "significant" and to prioritize a health need that, from a public health perspective on community health, may be relatively inconsequential.

\section{Whose Input?}

The Regulations are generally a model of indirection in telling hospitals what steps to take in conducting the assessment. One must infer from the Regulations' listing of the required elements of a hospital's CHNA documentation that hospitals should collect and analyze data and other information and have some process and criteria for identifying and prioritizing significant health needs. ${ }^{82}$ Because the CHNA is an established practice in public health and health planning, the IRS may have concluded that prescribing specific steps for the process would be unnecessary and overly constraining for hospitals. $^{83}$

By contrast, the Regulations' directions to hospitals on who must have a voice in the process are clear. To further the statutory requirement of community input, the Regulations provide that a hospital must solicit and take into account input from:

(i) At least one ... governmental public health department ... with knowledge, information, or expertise relevant to the health needs of that community;

(ii) Members of medically underserved, low-income, and minority populations in the community served $\ldots$ or individuals or organizations serving or representing [their] interests ...; and

(iii) Written comments received on the [hospital's] most recently conducted CHNA and most recently adopted implementation strategy. ${ }^{84}$

The hospital must consider this input in identifying and prioritizing the community's needs, as well as in identifying resources potentially available to meet those needs. ${ }^{85}$ As discussed below, ${ }^{86}$ the expected extent of the

$82 \S 1.501(\mathrm{r})-3(\mathrm{~b})(6)$.

83 American Hospital Association, Comment Letter on Proposed Rule Regarding Community Health Needs Assessments for Charitable Hospitals 2 (June 27, 2013) [hereinafter AHA Comments], http://www.aha.org/advocacy-issues/letter/2013/130627-aha-cl-irs-treasreg106499-12.pdf ("Congress ... had no need to prescribe how to do a 'needs assessment ...."”).

$84 \S 1.501(\mathrm{r})-3(\mathrm{~b})(5)(\mathrm{i})$.

$85 \mathrm{Id}$. The Regulations go on to provide a laundry list of additional sources of input (e.g., consumer advocates, academic experts, and healthcare providers) that the hospital may consider in its assessment). $§ 1.501(\mathrm{r})-3$ (b)(5)(ii).

86 See infra Section V.B.3. 
community's voice is less clear.

\section{Opportunities for Collaboration}

Support for collaborative approaches to assessing and addressing community health needs pervades the Regulations. The requirement that a hospital solicit and take into account input received from members or representatives of "medically underserved, low-income, and minority populations" and from a governmental health department opens the lines of communication and thus may lay a foundation for partnerships. However, beyond requiring hospitals to ask for and listen to input, the Regulations do not mandate any collaboration. ${ }^{87}$ They do indicate that when a hospital produces its "CHNA report"-documenting its assessment process and its prioritization of health needs-it should identify any parties it collaborated with in that process. ${ }^{88}$

A hospital that works with others in performing its health needs assessment ordinarily must produce its own individual CHNA report for its governing board to adopt. That said, if a hospital collaborated in conducting its CHNA, some parts of its report may be "substantively identical" to parts of another organization's report. ${ }^{89}$ It cannot, however, simply cut and paste the CHNA report of another hospital or health department. Only when collaborating hospitals and other organizations (like health departments) define their community to be the same and have conducted a CHNA together can collaborators produce a joint CHNA report. 90

Developing and executing its "implementation strategy" (the written plan describing how a hospital plans to address the significant health needs its CHNA identified) present similar opportunities for collaboration. ${ }^{91}$ The Regulations provide that as part of its implementation strategy, a hospital should describe any plans it has to collaborate in addressing community health needs. ${ }^{92}$ Moreover, a hospital may work with other hospitals, governmental departments, and nonprofit

87 Additional Requirements for Charitable Hospitals, 79 Fed. Reg. 78,954, 78,967 (Dec. 31, 2014) (to be codified at 26 C.F.R. pts. 1, 53, 602) (rejecting suggested requirement of collaboration).

$88 \S 1.501(\mathrm{r})-3(\mathrm{~b})(6)(\mathrm{ii})$.

89 According to $\S 1.501(\mathrm{r})-3(\mathrm{~b})(6)(\mathrm{iv})$, part of the report may be "substantively identical to portions of a CHNA report of a collaborating hospital facility or the other organization conducting a CHNA, if appropriate under the facts and circumstances." The regulations supply two examples of when including language from another organization's report could be appropriate.

$90 \S 1.501(\mathrm{r})-3(\mathrm{~b})(6)(\mathrm{v})$. The joint CHNA report must identify each hospital to which it applies. The Regulations also clarify that multiple hospitals involved in a single ACO can produce a joint CHNA report.

$91 \S 1.501(\mathrm{r})-3(\mathrm{c})(1)$.

$92 \S 1.501(\mathrm{r})-3(\mathrm{c})(2)$. 
organizations to figure out what to include in its implementation strategy. Teaming up to develop an implementation strategy does not ordinarily excuse a hospital from producing its own separate written plan "tailored to the particular hospital ..., taking into account its specific resources." ${ }^{93}$ But when a group of collaborators has produced a joint CHNA report, hospitals in the group may also adopt a joint implementation strategy, as long as it clearly identifies each hospital's particular role and responsibilities in carrying out the strategy's action plan. ${ }^{94}$

In sum, the final Regulations strongly endorse hospitals' ability to choose collaborative approaches to carrying out their new responsibility without requiring them to partner with others as they assess and address community health needs. Earlier versions did not explicitly endorse hospitals' collaboration with other hospitals or other organizations like health departments. ${ }^{95}$ The final Regulations thus reflect an important recognition of the value of collaboration and alignment in community health improvement efforts.

\section{Transparency and Accountability}

The ACA itself demonstrates commitment to transparency regarding the CHNA process, requiring hospitals to make their CHNA reports "widely available to the public." 96 The Regulations implement this requirement by directing hospitals to post their CHNA reports on a website and making hard copies available for public inspection at the hospital itself. ${ }^{97}$ Thus, anyone interested in learning about a hospital's CHNA process and findings can go online to find the report, or those without access to Internet, can pick up a copy at the hospital. By contrast, transparency requirements for a hospital's implementation strategy are much weaker. The Regulations permit a hospital either to make its implementation strategy available on a website or submit it as part of its annual Form 990 filing. Form 990 is also the locus for the hospital's sole obligation to report what it is actually doing to address community needs. ${ }^{98}$ Form 990 filings are publicly available by request to a hospital or the IRS, but neither is required to put those filings online. Although some organizations, like

$93 \S 1.501(\mathrm{r})-3(\mathrm{c})(4)$.

94 Id.

95 Community Health Needs Assessments for Charitable Hospitals, 78 Fed. Reg. 20,523, 20,532-33 (proposed Apr. 5, 2013 ) (to be codified at 26 C.F.R. pts. 1, 53).

9626 U.S.C. $\S 501(\mathrm{r})(3)(\mathrm{B})(\mathrm{ii})(2012)$.

$97 \S 1.501(\mathrm{r})-3(\mathrm{~b})(8)$.

98 A hospital must describe in Form 990 "the actions taken during the taxable year to address the significant health needs identified through its most recently conducted CHNA ... or, if no actions were taken with respect to one or more of these health needs, the reason(s) why no actions were taken." 26 C.F.R. $\S 1.6033-2(a)(2)(i i)(l)(3)$. 
GuideStar, collect the 990 Forms submitted by tax-exempt organizations and make them available on the Internet, the lack of direct and easy access to hospital reports of their community health activities decreases transparency.

Increasing transparency would enhance hospitals' accountability for the substantial financial benefits they receive from tax exemption. But the Regulations' accountability measures are also limited. As noted, hospitals must report annually the actions they have taken to meet the needs identified in their CHNA, but it is unclear how closely the IRS will scrutinize those reports. Moreover, the critical question is not simply what the hospital is doing, but whether its activities make a difference in meeting the community needs identified through the CHNA process. The final Regulations eliminated a provision that would have required implementation strategies to include a plan for evaluating the impact of hospitals' community health activities, but they added a requirement that subsequent CHNA reports include an evaluation of that impact. $^{99}$ This requirement of some evaluation of impact - while limited and nonspecific — at least lays a foundation for meaningful hospital accountability.

\section{E. A Lingering Question: Community Benefit and Community Health Needs}

The IRS Regulations go a long way in putting flesh on the statutory bones of the hospital's CHNA requirement. While I will argue below that the IRS should further refine its guidance to promote greater transparency, accountability, community engagement and collaboration in hospitals' compliance, the Regulations do make some important strides in these directions. Regrettably, they fail to fully answer an important question: Will a hospital's pursuit of broad community health improvement goals be deemed to meet both its CHNA obligations under $\S 501(\mathrm{r})$ and the community benefit standard?

\section{Does $\S 501(r)$ Compliance Fully Satisfy the Community Benefit Standard?}

According to the IRS, the ACA's new requirements (which reside in $\S 501(\mathrm{r})$ of the I.R.C.) do not displace the existing "community benefit" standard for hospital tax-exemption under $\S 501(\mathrm{c})(3)$, but instead represent additional requirements for those hospitals. ${ }^{100}$ Although the obligations to adopt certain billing and collection practices and to complete CHNAs are in addition to the requirement that a hospital be "charitable," the congressional objectives underlying $\S 501(\mathrm{r})$ appear to overlap significantly with the concept of community benefit as a marker of a hospital's charitable nature. Yet the

$99 \S 1.501(\mathrm{r})-3(\mathrm{~b})(6)(\mathrm{F})$.

100 Additional Requirements for Charitable Hospitals, 79 Fed. Reg. 78,954, 78,956 (Dec. 31, 2014) (to be codified at 26 C.F.R. pts. 1, 53, 602). 
Regulations fail to indicate to what extent a hospital's satisfaction of the new requirements may also serve to satisfy the preexisting requirement. ${ }^{101}$ In other words, if a hospital establishes a financial assistance policy, implements $\S 501(\mathrm{r})$ 's other protections for financially strapped patients, ${ }^{102}$ conducts its CHNA, and develops and pursues an implementation strategy on schedule, has that hospital provided sufficient "community benefit?" Or is it expected to do something more?

Logically, it would seem that a hospital that follows a sound process in assessing its community's health needs and then acts pursuant to an implementation strategy to respond to the significant health needs it has identified should be deemed to have provided a "community benefit." But does that hospital also need to continue providing some level of charity care, as it likely has in the past? The Regulations do not address that question. By the same token, ${ }^{103}$ it is uncertain whether a hospital that jumps through the hoops of CHNA compliance, but fails to take meaningful steps to address its community's most pressing health needs, can satisfy the community benefit standard simply by continuing to treat some patients who are uninsured or covered by Medicaid. Whether satisfaction of the new $\S 501(\mathrm{r})$ requirements can function as a substitute or alternative for the "community benefit" factors that the IRS set out in 1969, or whether they impose an additional layer of compliance, is simply unclear. ${ }^{104}$

Given the IRS's history of lax enforcement of the community benefit standard and the minimal accountability imposed regarding implementation strategies, that question may not trouble many hospitals initially. Nonetheless, the ambiguous interaction of the tax-exemption requirements becomes more salient for hospitals considering participation in broad collaborative efforts to address upstream causes of poor health. These efforts may redirect hospital resources away from activities-like providing charity care-traditionally seen as satisfying community benefit requirements. This ambiguity illuminates

101 See Community Health Needs Assessments for Charitable Hospitals, 78 Fed. Reg. 20,523, 20,523 (proposed Apr. 5, 2013) (to be codified at 26 C.F.R. pts. 1, 53) (describing the ACA's enactment of $\S 501(\mathrm{r})$ and stating, "The Affordable Care Act did not otherwise affect the substantive standards for tax exemption that charitable hospital organizations are required to meet under section 501(c)(3)").

102 See supra notes 57-59 and accompanying text.

103 See infra Section IV.B.2.

$104 C f$. Michael A. Stoto \& Colleen Ryan Smith, Community Health Needs Assessments? Aligning the Interests of Public Health and the Health Care Delivery System To Improve Population Health, INST. MED. 1 (2015), http://nam.edu/perspectives-2015-communityhealth-needs-assessments-aligning-the-interests-of-public-health-and-the-health-care-deliverysystem-to-improve-population-health (describing the CHNA requirement as "[i]ntended to leverage the "community benefits"" that hospitals are required to provide). 
HEALTH AND TAXES

another dimension of the Regulations' opacity.

\section{When Will "Community Building Activities" Count as Community Benefit?}

Section II.B describes how Schedule $\mathrm{H}$, which collects information on hospital community benefit expenditures, draws a distinction between community benefit expenditures and "community building activities." 105 By separating out spending on "community building activities" (which encompasses efforts to address some social determinants) ${ }^{106}$ from "community benefit" spending, Schedule $\mathrm{H}$ displays an understanding of "community benefit" that is more limited than the Regulations' vision of "community health needs." The IRS's message - at least when it first created Schedule H-was that "community building activities" do not count as a "community benefit." 107 This distinction left some hospitals confused about whether they could report as community benefit expenditure their investments in programs designed to improve their community's health, but falling within the Schedule's description of community building activities. This perplexing state of affairs may have led hospital administrators to stick with the safer (from a tax-exemption standpoint) route of engaging in activities, like charity care, that would be clearly reportable on the "community benefit" part of Schedule H.

After the ACA's enactment, the IRS made an encouraging, if not terribly clarifying, revision to the instructions for Schedule H. In 2011, it added a short sentence: "Some community building activities may also meet the definition of community benefit." This addition signals the IRS's willingness-in some cases-to treat hospital activities targeting non-medical determinants of health as providing community benefit. Unfortunately, the instructions do not specify when the IRS will do so, but rather direct a hospital wishing to claim community building activities as part of its community benefit expenditures to describe how those "promote the health of the communities it serves." As a result, a hospital wishing to respond to a community health need identified in its CHNA by participating in an initiative to address a social determinant of health is left uncertain whether the IRS would view that participation as community benefit. ${ }^{108}$

105 See supra text accompanying notes $46-48$.

106 The examples include "physical improvements and housing," "economic development," and "community support." Schedule H, supra note 46.

107 The original instructions for Schedule $\mathrm{H}$ stated that community benefit activities were not reportable as "community building activities." Id.

108 See Sara Rosenbaum et al., Encouraging Nonprofit Hospitals To Invest in Community Building: The Role of IRS 'Safe Harbors,' HeALTH AFF. BLOG (Feb. 11, 2014), http://healthaffairs.org/blog/2014/02/1 1/encouraging-nonprofit-hospitals-to-invest-incommunity-building-the-role-of-irs-safe-harbors; Supporting Alignment and Accountability in 


\section{HoSPITAlS AND POPUlATION HEALTH: EMBRACING CONVERGENCE?}

\section{A. Alignment with the $A C A$ 's Broad Goals}

The new CHNA requirement-while situated as a discrete provision regarding tax exemption-aligns both with the ACA's broader purposes and with increasing attention within the hospital industry to population health. Specifically, the CHNA requirement relates to the ACA's goals of providing health insurance for most Americans and increasing attention to prevention and public health. The decline in the number of uninsured Americans resulting from the ACA should produce an attendant decrease in the need for charity care. ${ }^{109}$ This decrease could call into question hospitals' reliance primarily on charity care to satisfy the community benefit standard. The CHNA requirement provides a different mechanism for hospitals to justify their tax exemption.

That new mechanism also connects directly with the ACA's preventive aim. The ACA incorporates measures increasing support for providing preventive care to individual patients and population-level health promotion. ${ }^{110}$ These measures range from requiring qualified health plans to cover preventive care without patient copayment obligations, to encouraging employer wellness programs, to commissioning a National Prevention Strategy, to increasing financial support for the public health workforce. ${ }^{11}$ In directing tax-exempt hospitals to look beyond providing medical services to patients and to address the health needs of their communities, the CHNA requirement aligns with the ACA's other public health-

Community Health Improvement, supra note 71, at 79-80.

109 Janet Corrigan et al., Hospital Community Benefit Programs: Increasing Benefits to Communities, 313 JAMA 1211, 1211 (2015) (reporting HHS's estimate that uncompensated care provided by hospitals will fall by $\$ 5.7$ billion in 2014). But see Brown, supra note 43 , at 4-5 (noting the continuing problem of underinsured patients' ability to pay hospital bills). In addition, uninsurance has declined less in states that have chosen not to expand Medicaid. See Assistant Sec'y for Planning \& Evaluation, Health Insurance Coverage and the Affordable Care Act, U.S. DEP'T HEALTH \& Hum. SERVS. 2 (2015), http://aspe.hhs.gov/sites/default/files/pdf/111826/ACA\%20health\%20insurance $\% 20$ coverage $\% 20$ brief\%2009212015.pdf.

110 See generally Laura Anderko et al., Promoting Prevention Through the Affordable Care Act: Workplace Wellness, 9 PREV. CHRONIC DIS. E175 (2012) (describing how the ACA's workplace wellness provisions reflect a focus on prevention and wellness); Frederic E. Shaw et al., The Patient Protection and Affordable Care Act: Opportunities for Prevention and Public Health, 384 LANCET 75 (2014) (describing ACA measures that emphasize prevention and spurring healthcare and public health collaborations to improve community health). But see Micah Berman, A Public Health Perspective on Health Care Reform, 21 HEALTH MATRIX 353, 355 (2011) (arguing that the ACA's understanding of public health is too narrow and does not reflect how most public health experts understand the field).

111 Shaw et al., supra note 110 , at 78-79. 
oriented provisions. Explicitly signaling this shift in orientation, the statute itself directs hospitals conducting CHNAs to take into account input from "persons ... with special knowledge of or expertise in public health." 112

\section{B. Convergence and Alignment with Public Health Objectives}

Despite the ACA's provisions that support preventive care and health promotion, some scholars have argued that the health reform law does not go far enough to adopt a public health perspective and to integrate public health approaches into the healthcare system. ${ }^{113}$ They assert that the most effective and efficient way to improve health outcomes in the United States is not simply to increase access to healthcare services, but to integrate what are currently two systems with distinctive focuses. ${ }^{114}$ The healthcare system "is concerned with the individual's care and treatment, while public health is concerned with the health and well-being of populations." 115 For directing hospitals (traditionally part of the healthcare system) to conduct community health needs assessments (traditionally a public health tool), the CHNA requirement is hailed as one example of convergence between healthcare and public health. ${ }^{116}$

Echoing this sentiment, public health professionals and scholars have noted eagerly the opportunity the CHNA requirement presents for aligning hospitals' community benefit schemes with health departments' community health improvement objectives. Public health agencies and professional organizations actively participated in the development of regulations. In particular, comments from the public health community commended the IRS's recognition of the vital contribution that health departments can make to the CHNA process. ${ }^{117}$

Similarly, public health scholars and commentators have welcomed the new collaborative opportunities the CHNA requirement seems likely to create. ${ }^{118}$ One

11226 U.S.C. $\S 501(\mathrm{r})(3)(\mathrm{B})(\mathrm{i})(2012)$.

113 See, e.g., Berman, supra note 110, at 355.

114 Gostin et al., supra note 16 , at 1781 .

$115 \mathrm{Id}$. at 1783.

$116 \mathrm{Id}$. at 1787.

117 In its comments on the IRS's 2013 proposed regulations, the National Association of County \& City Health Officials (NACCHO) concluded: "NACCHO believes that the CHNA requirements have great potential to promote new, mutually beneficial collaborations between non-profit hospitals and local health departments to improve the health of the communities each serves." National Association of County \& City Health Officials, Comment Letter on Proposed Rule Regarding Community Health Needs Assessments for Charitable Hospitals 5 (June 28, 2013), http://www.naccho.org/advocacy/action/upload/July-2013-NACCHOComments-to-IRS-CHNA-Proposed-Rule_FINAL.pdf.

118 See, e.g., Partner with Nonprofit Hospitals To Maximize Community Benefit Programs' Impact on Prevention, Tr. AM.'s HEalTH 2 (2013) http://www.healthyamericans.org/assets/files/Partner\%20with\%20Nonprofit $\% 20$ Hospitals04. 
hails the law as "creat[ing] a powerful platform for an implementation strategy that ultimately yields a national system of community health needs assessments and implementation strategies that in scope parallels the law's broad concept of community health transformation." ${ }^{\prime 19}$ Another predicts that the requirement will "provide[] incentive for the [non-profit] hospital to go in a direction in which the public health sector has been going for a number of years-to utilization of models of citizen participation and public-private partnerships." ${ }^{20}$ Scholars note the concrete benefits of collaboration among hospitals, health departments, and community organizations: avoiding duplication of effort and permitting hospitals to access public health expertise and skills relating to developing population health measures, interpreting data, and engaging community members. ${ }^{121}$

These rosy expectations of increased collaboration find support in the experience in California, which has had a community health assessment requirement for hospitals since 1994. Reporting to the California Legislature in 1998, California's Office of Statewide Health Planning and Development observed:

An unforeseen dividend of SB 697 was a stimulus for community-wide, collaborative health planning on a scale that has not been witnessed for many years. Perhaps this should not have been too surprising, for this broader-gauged planning is the natural extension of individual hospitals conducting needs assessments and benefit planning together with other interested parties in the community. ${ }^{122}$

pdf (asserting that the CHNA requirement provides "new opportunities for nonprofit hospitals to partner with state and local health departments, local employers and businesses and community groups to increase their understanding of the needs of the community").

119 Sara Rosenbaum \& Ross Margulies, Tax Exempt Hospitals and the Patient Protection and Affordable Care Act, 126 PUB. HeAlth ReP. 283, 284 (2011); see also Michael A. Stoto, Community Health Needs Assessments-An Opportunity To Bring Public Health and the Healthcare Delivery System Together To Improve Population Health, IMPROVING PUB. HEALTH (Apr. 16, http://www.improvingpopulationhealth.org/blog/2013/04/community-health-needsassessments-an-opportunity-to-bring-public-health-and-the-healthcare-delivery.html (describing the CHNA requirement as "the key" to managing shared responsibilities for improving community health).

120 Ann L. Abbott, Community Benefits and Health Reform: Creating New Links for Public Health and Not-for-Profit Hospitals, 17 J. Pub. Health Mgmt. \& Practice 524, 528 (2011).

121 Jean O'Connor et al., Paying for Prevention: A Critical Opportunity for Public Health, 2012 Pub. Health L. CONF. 69, 70-71 (2013).

122 State of Cal., Office of Statewide Health Planning \& Dev., Not-for-Profit Hospital Community Benefit Legislation (SENATE BILl 687): Report to the 


\section{Barriers to Alignment}

Not everyone has been sanguine about hospitals' embracing a new community orientation and collaborating with community partners. While noting potential benefits of collaboration, the Hilltop Institute adds a caution: "Collaborative approaches to CHNA ... may not be easy to achieve. Partnerships between hospitals and public health agencies may present challenges in achieving a common focus in the face of differing philosophies and priorities." 123 Writing before the ACA's enactment, Dr. Stephen Shortell described overlapping strategic, cultural, technical, and structural barriers to engaging hospitals in community health efforts. Hospitals' central strategic priority is providing high quality acute care and emergency services to its patients (strategic). Health professionals working in hospitals thus understand their roles as providing medical care to sick or injured patients, not as promoting health or engaging communities (cultural). Most hospitals lack staff with public health training, population-level health data to support a needs assessment for a specific geographic area, and internal policies promoting community outreach and engagement with public health agencies (technical and structural). ${ }^{124}$

The foregoing barriers are largely internal to hospitals. But even hospitals that overcome these barriers and seek to partner with health departments to improve community health may face a different set of challenges. These challenges flow from system-level differences between the medical care and public health systems in culture, orientation, and priorities, and the resulting difficulty in communicating clearly and establishing trust. ${ }^{125}$

Perhaps the most daunting impediments to hospitals devoting serious attention to community health improvement, though, lie in how hospitals are paid $^{126}$ and the competitive nature of the hospital market. Most existing

\section{LEGISLATURE 31 (1998).}

123 Donna C. Folkemer et al., Hospital Community Benefits After the ACA: Building on

State Experience, HILlTOP INST.
http://www.hilltopinstitute.org/publications/HospitalcommunityBenefitsAftertheACA-

HCBPIssueBrief2-April2011.pdf.

124 Shortell et al., supra note 24 , at 379-80.

$125 C f$. LAWrence Prybil et al., Improving Community Health Through HospitalPublic Health Collaboration: InSights and Lessons Learned from SucCessful PARTNERSHIPS 40

(2014),

http://uknowledge.uky.edu/cgi/viewcontent.cgi?article=1001\&context=hsm_book (emphasizing the importance of trust among successful hospital-public health partnerships).

126 Cf. Strategic Investment in Shared Outcomes: Transformative Partnerships Between Health Systems and Communities, Health Sys. Learning Group 23 (2013) [hereinafter Health Sys. Learning Group Monograph], http://stakeholderhealth.org/wpcontent/uploads/2013/09/HSLG-V11.pdf (noting the "perverse incentives in the current 
reimbursement systems pay hospitals for treating patients who are sick or injured. $^{127}$ By and large, hospitals receive no compensation for keeping community members healthy and out of the hospital. One need not be a cynic to question how vigorously hospitals will pursue efforts that-if successful-will diminish their revenue streams. Recent efforts to reorient reimbursement schemes to incentivize preventive care, disease management, community-based care, and health promotion, ${ }^{128}$ while promising, may be unlikely in the near term to overcome the "fill the beds" incentives that still exist. ${ }^{129}$ Similarly, hospitals" efforts to edge ahead of other local hospitals in attracting physicians, patients, and payers - and the attendant revenue - are unlikely to lead them to emphasize services and programs for community members with the greatest need. Additionally, the hospitals located in the communities with the greatest need may be the least able financially to make investments in population health-oriented measures, even if they are motivated to do so. ${ }^{130}$

\section{Hospitals' Reaction and Its Importance}

While less jubilant than public health professionals about their new community-health-oriented obligations, hospitals have tended not to complain too loudly—perhaps out of relief at avoiding more onerous requirements. ${ }^{131}$ Even

system of fee-for-service financing").

127 See O'Connor et al., supra note 121 , at 71 (making this point more broadly with respect to the need for payment mechanisms for community-level prevention strategies).

128 A particularly intriguing experiment began recently in Maryland, where the State and its hospitals have agreed with CMS to shift most of the hospitals' revenue into global budgets, thus moving away from the traditional fee-for-service model. See Ankit Patel et al., Maryland's Global Hospital Budgets-Preliminary Results from an All-Payer Model, 373 NEW ENG. J. MED. 1899, 1899 (2015). For a brief discussion of some additional efforts, see infra Section IV.E.

129 Cf. Shortell et al., supra note 24, at 380 (asserting that the most important policy issue for encouraging greater hospital engagement in community health promotion is "changes in health care payment systems for hospitals that create incentives for broader-based community health investment" and suggesting some alternatives); Martha H. Somerville et al., Hospitals, Collaboration, and Community Health Improvement, 43 J.L. MED. \& ETHICS 56, 58 (2015) (suggesting that new reimbursement methods "may inadequately address the higher costs associated with serving the most vulnerable and needy populations").

130 See Somerville et al., supra note 129 (noting competitive pressures as a challenge to collaboration).

131 Steven Ross Johnson, Obamacare Rule Has Hospitals Targeting Health Improvement, MODERN HEALTHCARE (June 14, 2014), http://www.modernhealthcare.com/article/20140614/MAGAZINE/306149803 (quoting a representative of the AHA). One might think that, given the value of tax exemption to hospitals, the risk of losing tax-exempt status would provide a countervailing financial 
before the ACA's passage, hospitals' potentially important role in partnerships aimed at improving health at the population, rather than patient, level was increasingly recognized. ${ }^{132}$ Indeed, hospitals' assessing and attending to community health concerns were not entirely new, even if the legal requirement to do so was. Some hospitals and health systems assessed community health needs in order to target their services to particular needs and to raise community awareness and support. ${ }^{133}$

The hospital industry played an active role in the development of the regulatory guidance on the CHNA requirement. Industry comments on proposed regulations stressed the desirability of "avoiding detailed or prescriptive requirements that create unnecessary burden and limit [hospitals'] appropriate flexibility."134 Multiple hospital commenters urged the IRS not to require hospitals to take into account input from public health officials, expressing concern that demanding consultation with thinly staffed health departments could affect hospitals' ability to comply. ${ }^{135}$ But hospital commenters generally did not object on principle to working with public health departments or consulting with community members; instead, they expressed openness to that engagement. ${ }^{136}$

Despite the Regulations' long gestation and the attendant uncertainty as to the precise contours of the CHNA obligations, hospitals had no choice but to begin conducting assessments and developing implementation strategies in order to meet the ACA's deadline for the CHNA requirement. ${ }^{137}$ In doing so, a good number of hospitals have gone beyond minimal compliance, embracing

incentive. In light of the history of lax IRS enforcement and the lack of meaningful accountability measures in the regulations, hospitals may be unlikely to perceive the potential loss of tax-exempt status as a real threat.

132 See Shortell et al., supra note 24, at 374.

133 Michael Bilton, Community Health Needs Assessment, TrusteE, Oct. 2011, at 21, 24.

134 AHA Comments, supra note 83, at 2.

135 See, e.g., Matthew L. Anderson, Proposed Rule in Community Health Needs Assessments for Charitable Hospitals, MinN. Hosp. Ass'N (July 3, 2013), www.mnhospitals.org/policy-advocacy/commentletters/articletype/articleview/articleid/193/proposed-rule-on-community-health-needsassessments-for-charitable-hospitals (comment submitted electronically in response to REG106499-12; Community Health Needs Assessments for Charitable Hospitals Proposed Rule by MHA's Vice President for Regulatory/Strategic Affairs).

136 Id. ("[T]he CHNA requirement has already generated a more robust level of collaboration and communication between hospitals and local public health agencies.").

137 Pub. L. No. 111-148, § 9007(f), 124 Stat. 119, 859 (2010) (codified at I.R.C. $\S 501$ (2012)) (requiring hospitals to conduct a CHNA within the three-year period that commenced on the first day of the hospital's first tax year that began after March 23, 2010 and ended on the final day of its first tax year that began after March 23, 2012). 
opportunities to engage closely with community members and other stakeholders in efforts to address vexing community health issues. This Article urges the IRS to encourage such efforts by providing clear guidance emphasizing the need for transparency, accountability, and community engagement and the value of collaboration. Realistically, though, the history of lax IRS enforcement of the community benefit standard and current reality of shrinking agency budgets suggest it is unlikely that the IRS will closely police hospitals' compliance with whatever guidance it provides. As a result, the effectiveness of any guidance in shaping hospital conduct will depend partly on how receptive hospitals are. Evidence presented below suggests that a significant number of hospitals, rather than resisting the shift of orientation that the CHNA requirement contemplates, may be open to guidance on how best to accomplish it.

Hospitals are extremely heterogeneous, varying widely in terms of size, location, mission, and other factors. ${ }^{138}$ Thus, broad generalizations about their preexisting commitments to community health improvement, or about their likely reactions to additional regulatory guidance on the CHNA requirement are not possible. That said, this Article's thesis does not depend on showing that its recommended regulatory guidance would change the behavior of all, or even a large majority of tax-exempt hospitals. Instead, the IRS's opportunity is to help normalize community and public health orientations within the hospital industry. ${ }^{139}$ It can do so by establishing official expectations regarding hospitals' evolving role in promoting population health. Fostering a norm of community orientation can shape what hospitals expect of themselves.

A shift in the right direction in many hospitals' engagement with their communities and interest in promoting population health is already underway. ${ }^{140}$ This movement likely results from a combination of economic and political stimuli, including accelerating initiatives to tie hospital reimbursement to qualityand value-related factors, pressure to address health disparities, and a desire to redeem hospitals' reputation within their communities after widespread media criticism. This Section shows that-whatever the reasons-a meaningful number of hospitals are already engaging with their communities to promote community

138 Lindsey Dunn \& Scott Becker, 50 Things To Know About the Hospital Industry, BECKER'S HOSP. REV. (July 23, 2013), http://www.beckershospitalreview.com/hospitalmanagement-administration/50-things-to-know-about-the-hospital-industry.html (categorizing hospitals as nonprofit, for profit, government entities, rural, safety net, and academic medical centers).

139 Cf. Susan Sturm, Law's Role in Addressing Complex Discrimination, in HANDBOOK of EMPloyment Discrimination RESEARCH 35 (Laura B. Nielsen \& Robert L. Nelson eds., 2005) (describing how legal norms develop not only through liability determinations, but also through legally structured occasions for deliberating about the relationship between norms and practice).

140 See infra Section IV.E. 
health, often as part of a collaboration, and that even more hospitals are thinking and talking about doing so. This Section thus supports an assertion that a meaningful segment of the hospital industry would be receptive and responsive to further guidance by the IRS.

\section{E. Hospitals' Attention to Population Health}

\section{Advice from the American Hospital Association}

Even before the new CHNA requirement went into effect, many hospitals were reconceiving their roles in improving health. A series of reports from the AHA (the "AHA Reports") discuss the strategic importance to hospitals of prioritizing "population health" in response to changes in the healthcare and reimbursement environment. ${ }^{141}$ The AHA Reports sound a central theme: managing and improving "population health" entails adopting a broader frame of reference than hospitals are accustomed to. One report describes it as "the shift from managing individuals to managing populations." ${ }^{142}$ Yet this expanded frame of reference still often targets the population of hospital patients. ${ }^{143}$ This "patient population" frame of reference likely overlaps, but is not entirely congruent with, the community whose needs hospitals are supposed to assess under the ACA. The law's reference to "community health needs" suggests a geographic basis for defining the population whose needs matter. It directs hospitals to consider the health needs of people living in their environs, even if those people have never set foot into the hospital itself. ${ }^{144}$

The AHA Reports point to the new CHNA requirement as one impetus

141 See, e.g., Managing Population Health: The Role of the Hospital, AM. HoSP. Ass'N (2012) [hereinafter Managing Population Health], http://www.hpoe.org/ReportsHPOE/managing_population_health.pdf; The Role of Small and Rural Hospitals and Care Systems in Effective Population Health Partnerships, AM. HOSP. ASs'N (2013) [hereinafter Role of Small and Rural Hospitals], http://www.hpoe.org/ReportsHPOE/The_Role_Small_Rural_Hospital_Effective_Population_Health_Partnership.pdf; The Second Curve of Population Health, AM. HosP. Ass'N (2014), http://www.hpoe.org/ReportsHPOE/SecondCurvetoPopHealth2014.pdf; Trends in Hospital-Based Population Health Infrastructure: Results from an Association for Community Health Improvement and American Hospital Association Survey, AM. Hosp. Ass'N (2013), http://www.hpoe.org/Reports-HPOE/ACHI_Survey_Report_December2013.pdf.

142 Managing Population Health, supra note 141, at 7.

143 See id. at 3 (asserting that hospitals should "examine how to manage the health of their patient populations to improve outcomes").

144 PRYBIL ET AL., supra note 125, at 42 (noting the need for collaboration partners to share common understandings of "population health concepts, definitions, and principles"); $c f$. Rosenbaum, supra note 77 ("The final rules ... underscore that the key issue is the community that needs the care of the hospital, not simply current patients.") (emphasis added). 
among several for increased attention to population health improvement. Other factors pushing hospitals in this direction are "external forces to simultaneously reduce cost, improve quality, and implement value-based payment programs." Also prompting the shift are other provisions of the ACA, such as denials of payment for hospital readmissions and the support of pilot or demonstration programs creating medical homes and accountable care organizations. ${ }^{146}$ Woven through the AHA Reports is the message that the world hospitals have operated in for the past half century - a world dominated by reimbursements for discrete services for individual patients-is changing quickly, and hospitals need to adapt to the current environment and be ready for changes yet to come. Improving their ability to manage population health "will be essential for care delivery in the future value-based market." ${ }^{\prime 147}$

The AHA Reports advise hospitals on how to pursue this seemingly radical reorientation of their community commitments. At the core of this advice is the need for partnership: "[t]rue population health is not an outcome that hospitals and health systems will be able to achieve without collaboration and shared ownership of goals with other sectors." ${ }^{148}$ Partnering with other actors within the healthcare system (like physicians), with payers and employers, and with social services agencies, public health departments, and community organizations can help hospitals reach a broader swath of community members and permit the sharing of financial, personnel, and knowledge resources. Thus, for example, hospitals might partner with physicians to improve care coordination for highcost patients, with hospitals providing data about clinical encounters to identify variations in care and show best practices and physicians supplying the ongoing patient interaction critical to behavioral change. ${ }^{149}$ Alternatively, a hospital might collaborate with community cultural organizations to develop outreach mechanisms to encourage screenings, connect neighborhood residents to primary care providers, and supply culturally appropriate information about diet and healthy living. ${ }^{150}$ As the AHA Reports emphasize, efforts to improve population health will look different across the range of hospitals, as hospitals' missions and available resources vary. ${ }^{151}$ The AHA's suggestions provide hospitals tools for beginning to develop their own population health strategies. ${ }^{152}$

145 Managing Population Health, supra note 141, at 3.

$146 I d$. at 5 .

$147 \mathrm{Id}$. at 6

148 Id. at 9.

$149 \mathrm{Id}$. at 12 .

$150 \mathrm{Id}$. at 15 (providing examples).

151 Id. at 9; see also Role of Small and Rural Hospitals, supra note 141, at 7-8 (describing the particular challenges and opportunities that small and rural hospitals face in seeking to address population health).

152 Another resource for hospitals is the ACHI Community Health Assessment Toolkit, 


\section{Hospitals Pursuing Population Health: Some Examples}

Indeed, finding examples of hospitals pursuing initiatives to address community health needs, whether alone or as part of a network, has become easy. While not attempting to survey hospital practices comprehensively, this Section illustrates the diversity of approaches that hospitals can take and demonstrates the plausibility ${ }^{153}$ of hospitals' playing meaningful roles in such initiatives. In doing so, it also highlights potential models for informing the IRS's refinement of its guidance to hospitals. These examples embody the shift away from conceptualizing "community benefit" as entailing primarily uncompensated hospital care for individual patients. Instead, their expanded frames of reference encompass the hospitals' communities. They vary significantly in how broadly they understand community health needs and hospitals' roles in responding to them.

Contrasting examples appear in a 2014 article on the Modern Healthcare website describing two hospitals' responses to needs identified in their community needs assessments. ${ }^{154}$ According to the article, Advocate Trinity Hospital learned from its assessment that its community on Chicago's South Side suffered high rates of stroke and that heart disease, and that cancer produced more than half the deaths in its service area. In response to this information, the hospital invested in a primary stroke center to shorten the distance that patients suffering stroke would have to travel and in a second heart catheterization lab and new radiology equipment. ${ }^{155}$ Assessments conducted by the Henry Ford Health System, based in Detroit, revealed that heart disease, diabetes, and infant mortality were the most pressing issues for its community stakeholders. To address those issues, Henry Ford chose to partner with community organizations to tackle lack of prenatal care and low birth weight, both contributors to infant mortality. The hospital-community partnership trains navigators who work to identify at-risk women in their neighborhoods and to connect them to community

AM. HosP. Ass'N (2007), http://www.assesstoolkit.org. The Association for Community Health Improvement is also affiliated with the AHA.

153 Of course, the plausibility or viability of any particular hospital's effort to collaborate with community partners on broad initiatives depends on numerous factors, including the hospital's mission, leadership, competitive position within its market, financial situation, and the availability and interest of community partners. Another factor present in several states are laws imposing on nonprofit hospitals a minimum level of charity case expenditures as a condition of state tax exemption. See, e.g., NEv. REv. STAT. $§ 439$ B.320 (2015). Hospitals in these states will have less flexibility to redirect community benefits investments towards community health initiatives.

154 See Johnson, supra note 131.

155 Id. 
resources. $^{156}$

Both hospitals are responding to health needs that they would not have identified had they focused only on patients' individual health needs. They each assessed needs at the community level and asked what gaps they might fill in addressing the needs identified. But the natures of their responses differ notably. According to the article, Trinity Hospital's response to high rates of stroke and deaths from heart disease and cancer in its community was to beef up the medical services available to patients with those conditions. By contrast, Henry Ford responded by partnering with community-based organizations to establish a neighborhood presence designed to help prevent the health issues identified in the assessment from arising in the first place.

Drawing this distinction does not detract from the value of Trinity's response. By investing in the creation of a primary stroke center, it ameliorated a geographic barrier to stroke victims' accessing appropriate care, and geographic barriers may contribute to health disparities. ${ }^{157}$ But when Henry Ford identified infant mortality as a big problem, it joined community partners to work in neighborhoods promoting the health of pregnant women--and ultimately their babies-by connecting them with a range of resources. It understood that the most effective response to some health needs lies not in more and better medical care, but in addressing aspects of community life that undermine health, or the social determinants of health. This latter, less conventional (for hospitals, anyway) approach to promoting community health is what I argue the IRS should more forcefully encourage and facilitate in its guidance to hospitals by focusing on the values described in Part V.B.

Some hospitals have begun working together to exchange information about innovative approaches to community health partnerships, ${ }^{158}$ and a burgeoning

\section{Id.}

157 Cf. Renee Hsia \& Yu-Chu Shen, Possible Geographical Barriers to Trauma Center Access for Vulnerable Patients in the United States: An Analysis of Urban and Rural Communities, 146 ARCHIVES SURGERY 46 (2011) (finding that certain vulnerable groups are at higher risk of poor access to trauma centers); Michelle L. Mayer, Disparities in Geographic Access to Pediatric Subspecialty Care, 12 Maternal \& ChILd Health J. 624 (2008) (identifying characteristics of populations at risk for poor geographic access).

158 See Health Sys. Learning Group Monograph, supra note 126. The Health Systems Learning Group (HSLG) included thirty-six non-profit health systems seeking, in response to the ACA's passage, "to identify and activate a menu of proven community health practices and partnerships that work from the top of the mission statement to the bottom line.... [to identify] new pathways to transform unmanaged charity care into strategic, sustainable community health improvement." Id. at 10 . These hospitals also recognize that community partnerships engaging a broad range of community stakeholders are needed to address many community health needs and that a hospital's role in supporting community health transformation will often be that of supporting partner, rather than lead actor. Id. at 14 ("In many cases, the hospital may not take the lead, but will provide strategic support in a defined 
literature $^{159}$ describes hospitals' engagement in a wide range of activities to address community health needs. ${ }^{160}$ Examples include a Memphis hospital's partnership with five hundred congregations to create a Congregational Health Network, which hired congregational navigators to connect with volunteer liaisons in each congregation and work as community care coordinators arranging post-discharge services; ${ }^{161}$ the participation of Camden hospitals in the Camden Coalition, which created a "hot spotting" approach to identifying heavy users of medical care and meeting their needs in the community, thus decreasing avoidable emergency room visits; ${ }^{162}$ and Advocate Christ Medical Center's partnership with the community organization CeaseFire to develop the Chicago region's first hospital-based program focused on preventing gun violence by employing trained "violence interrupters" as well as community-based outreach workers. ${ }^{163}$ Other hospitals are participating in medical-legal partnerships, which add lawyers to the team providing patient care to help address legal or social issues underlying patients' poor health. ${ }^{164}$ Initiatives are not limited to urban

area."). In July 2013 the group changed its name to Stakeholder Health. See STAKEHOLDER HEALTH, http://stakeholderhealth.org (last visited Jan. 4, 2016).

159 See, e.g., Martha Hostetter \& Sarah Klein, Improving Population Health Through Communitywide Partnerships, QUALITY MATTERS NEwSL. (Feb. 23, 2012), http://www.commonwealthfund.org/publications/newsletters/quality-matters/2012/februarymarch/in-focus; Martha H. Somerville et al., Hospital Community Benefits After the ACA: Partnerships for Community Health Improvement, HILLTOP INST. 1 (2012), http://www.hilltopinstitute.org/publications/HospitalCommunityBenefitsAfterTheACA-

HCBPIssueBrief3-February2012.pdf (describing "partnerships among public health agencies, nonprofit hospitals, and the communities they serve"); Health Sys. Learning Group Monograph, supra note 126.

160 Some of these hospital activities followed the completion of an ACA-mandated CHNA, while other initiatives preceded the ACA requirement or were prompted by other concerns. This Section simply provides examples of the diverse activities hospitals are engaged in, without asserting that the stimulus for a particular hospital's community-focused effort was the new CHNA requirement. Similarly, it is difficult to discern from the literature how many of these initiatives are likely to be sustained for long enough to have a significant impact on community health.

161 Health Sys. Learning Group Monograph, supra note 125, at 33 (describing efforts of Methodist Le Bonheur Hospital).

162 See About the Camden Coalition, Camden Coalition HealthCare Providers, http://www.camdenhealth.org/about/about-the-coalition/history (last visited Jan. 4, 2016) (describing the history of the Coalition); Atul Gawande, The Hot Spotters, New YORKER (Jan. 24, 2011), http://www.newyorker.com/magazine/201 1/01/24/the-hot-spotters.

163 See Health Sys. Learning Group Monograph, supra note 126, at 71.

164 See generally Ellen M. Lawton \& Megan Sandel, Medical-Legal Partnerships Collaborating To Transform Healthcare for Vulnerable Patients, A Symposium Introduction and Overview, 35 J. LEG. MED. 1, 3-4 (2014) (describing the structure and expansion of the medical-legal partnership model and its potential to address legal contributions to the social 
hospitals. Hospitals in sixteen mountainous and mostly rural North Carolina counties have partnered with local health departments to establish Western North Carolina Healthy Impact, which coordinates a collaborative CHNA, and the hospitals have aligned their individual implementation strategies with the broader, community-wide health improvement plan. ${ }^{165}$ These examples just begin to describe the diverse ways hospitals can engage in community-centered strategies to address community health needs. ${ }^{166}$

These examples-and others like them-also provide the data for nascent research into how hospitals are actually engaging with their communities and the development of best practices ${ }^{167}$ for community health improvement initiatives. A project undertaken by the Public Health Institute to develop a set of online tools for comparing the assessment, planning, and implementation processes that hospitals are using in carrying out their CHNA obligations ${ }^{168}$ is an example of this research. ${ }^{169}$ This project's purpose is to assist hospitals and other entities seeking to pursue community health improvement, and particularly to support the alignment of resources in communities with significant health disparities. The results of this pilot study of CHNA reports from a random sample of forty-four hospitals reflect, according to the authors, "a practical reality that there are considerable opportunities for enhancement in most communities." ${ }^{\prime 170}$ To be

determinants of health).

165 See Martha H. Somerville et al., Hospital Community Benefits After the ACA: Present Posture, Future Challenges, HiLloP INST. 10-11 (2013), http://www.rwjf.org/content/dam/farm/reports/issue_briefs/2013/rwjf408710.

166 For other examples, see Christine Fry et al., Health Reform, Healthy Cities: Using Law and Policy To Reduce Obesity Rates in Underserved Communities, 40 FORDHAM URB. L.J. 1256, 1288-89 (2013) (describing obesity-prevention initiatives of Cedar Sinai Hospital in Los Angeles and New York Presbyterian Hospital in New York City).

167 See, e.g., Kevin Barnett, Best Practices for Community Health Needs Assessment and Implementation Strategy Development: A Review of Scientific Methods, Current Practices, and Future Potential, PUB. HEALTH INST. (2012), http://www.phi.org/uploads/application/files/dz9vh55o3bb2x56lcrzyel 83 fwfu3mvu24oqqvn5z 6qaeiw2u4.pdf.

168 See Supporting Alignment and Accountability in Community Health Improvement, supra note 71 . This project is being funded by Centers for Disease Control and Prevention through a cooperative agreement with the National Network of Public Health Institutes.

169 Other examples include Karen Wade \& Gene W. Matthews, Review of North Carolina Hospitals' Community Health Needs Assessments and Implementation Strategies, $\begin{array}{lllll}\text { NETWORK FOR PUB. } & \text { HEALTH }\end{array}$ https://www.networkforphl.org/_asset/rl gg6w/Network-NC-CHNA-Report.pdf; Supporting Alignment and Accountability in Community Health Improvement, supra note 71; and Tahk, supra note 7, at 59-64 (analyzing data from 2012 tax returns for all tax-exempt hospitals in the United States).

170. Wade \& Matthews, supra note 169 , at 6. 
blunt: there is a lot of room for improvement. In particular, the findings suggest the need for clarification and assistance relating to how a hospital defines its community; the role and extent of community input; how health needs are prioritized; how interventions are targeted geographically to address health disparities; and how hospitals develop tools to evaluate their community health activities. $^{171}$

In summary, this Part demonstrates that the hospital industry recognizes the need for increased attention to population health, that numerous hospitals and health systems already are engaged in efforts to improve their communities' health, and that initial research into hospitals' CHNA compliance activities finds ample room for improvement in connecting compliance to community health advances. Together, these findings suggest the importance of further guidance from the IRS to help harness and direct the substantial investment hospitals are making in the CHNA enterprise. The broad goals of such guidance should be to maximize the prospect of those investments" "moving the needle" both in addressing community health needs and in producing meaningful knowledge about how to do so. Thus, they set the stage for this Article's final Part.

\section{THE OPPORTUNITY GOING FORWARD}

This Article posits that targeted regulatory guidance on hospitals' new CHNA obligation is critically important to maximizing the potential for community health improvement. Having described the existing regulatory framework and approaches already percolating in the hospital community, the final step is to consider how the IRS's regulatory approach could be more effective. To that end, this Part will first note some broad considerations regarding the IRS's role in making health-related policy. Then it will examine in greater depth the four substantive values the IRS should promote going forward, explaining their importance and suggesting ways to advance each of them. It will close with a few ideas on mechanisms the IRS might consider for promoting those values.

\section{A. The IRS as Health Policy Maker}

Questioning the desirability of the IRS's central role in formulating health policy through its administration of tax-exemption standards is not novel. ${ }^{172}$ Thus, before a discussion describing what the IRS should do to refine its CHNA guidance going forward, pausing briefly to address why this Article focuses on the IRS's role at all is in order. As described above, the IRS did not historically

171 Id. at 5-6.

172 See, e.g., Fox \& Schaffer, supra note 36 , at 266-67. 
(at least until the last decade) pay much attention to hospital tax exemption. ${ }^{173}$ Its long-term track record does not augur well for its paying close and creative attention to enforcing the CHNA requirement. Moreover, as an agency whose primary focus is collecting revenue, its staff cannot be expected to bring a deep level of expertise or understanding to the project of refining the CHNA guidance to help accomplish community health goals. ${ }^{174}$

Notwithstanding these legitimate questions, asking the IRS to play an important role now and in the coming years is justified. The agency's recent Schedule $\mathrm{H}$ initiative to collect community benefit information from hospitals and its engagement with diverse stakeholders in the promulgation of the Regulations demonstrate a commitment to closer oversight of tax-exempt hospitals. In addition, using the Tax Code to accomplish health policy goals accords with the IRS's growing role in administering social welfare policy more broadly. ${ }^{175}$ The agency's "to do" list from the ACA alone is long and complex, ${ }^{176}$ suggesting that it will develop increasing expertise in health matters. Indeed, given the broad demands of ACA implementation and a shrinking agency budget, ${ }^{177}$ the pertinent question may be whether the IRS will have the resources to pay more than cursory attention to the CHNA requirement now that it has issued the Regulations.

Yet investing resources in the further refinement of the CHNA guidance could bear valuable fruit. As discussed in Part III.E, forces are pushing hospitals to increase their focus on population health. The IRS has an opportunity to leverage these forces so that hospitals' investments in population health are channeled in socially optimal directions, rather than being driven solely by hospitals' economic interests. The resources at stake are enormous. As Chris Kabel has pointed out, if tax-exempt hospitals were to invest in primary preventive care just twenty percent of their current community benefit expenditures on uncompensated and discounted care, the investment would be about $\$ 2.2$ billion annually. This amount exceeds Congress's annual allocation to

173 See supra Section II.A.

174 See King v. Burwell, 135 S. Ct. 2480, 2489 (2015) (making a similar observation in deciding not to grant Chevron deference to IRS regulations relating to the availability of tax subsidies for health insurance purchases under the ACA: "[i]t is especially unlikely that Congress would have delegated this decision to the IRS, which has no expertise in crafting health insurance policy of this sort.") (emphasis in original).

175 See generally Susannah Camic Tahk, The Tax War on Poverty, 56 ARIz. L. REv. 791 (2014) (describing increasing reliance on IRS to administer poverty-reducing programs).

1761 InTERNAl REVENUE SERV., 2014 ANNUAL REPORT to CONGRESS 67, 77 (2014), http://www.taxpayeradvocate.irs.gov/Media/Default/Documents/2014-AnnualReport/HEALTH-CARE-IMPLEMENTATION-Implementation-of-the-Affordable-Care-ActMay-Unnecessarily-Burden-Taxpayers.pdf.

$177 \mathrm{ld}$. at 68 . 
the Prevention and Public Health Fund, the federal government's largest commitment to prevention. ${ }^{178}$

Hospital involvement in promoting community health will doubtless evolve over time. But if the IRS fails now, at the beginning, to play a leading role in promoting transparency, accountability, community engagement, and collaboration in hospitals' compliance activities, other narratives may take hold and produce less desirable patterns of hospital behavior. Once patterns are established, influencing how hospitals conduct their CHNAs will be far more difficult. ${ }^{179}$ For that reason, it is important that the IRS not take it eye off the ball just because it has issued the CHNA Regulations.

Admittedly, hospitals are unlikely to welcome any proposal that the IRS enhance its oversight of the CHNA requirement. For hospitals conducting a CFNA for the first time, the process undoubtedly demanded significant energy and resources. Enhancing the IRS's regulatory guidance as suggested in this Part, however, need not increase the compliance burden on hospitals and may even, to the extent that hospitals collaborate to assess and address community health needs, decrease it. Further guidance can simultaneously establish clear expectations for hospitals and, recognizing the diversity of hospitals' situations, permit significant flexibility in how those expectations are met. Combining clear expectations regarding transparency, accountability, and community engagement with significant flexibility will encourage collaboration and facilitate hospitals' meaningful efforts to address community health issues.

In developing the Regulations, the IRS sought to strike this balance, including elements of both flexibility and standards. The Regulations tilt towards unconstrained decision making by hospitals, however, in the areas of identifying and prioritizing needs. In granting hospitals unfettered discretion to decide which health needs are significant and then to prioritize them, the Regulations make it too easy for hospitals to "think small" and thus decrease hospitals' incentive to partner with others in broader or more challenging community health projects. This Article proposes an antidote that emphasizes process-oriented values rather than substantive prescriptions in order to accommodate hospital diversity while encouraging the institutions to "think big" about their potential contributions to community health. ${ }^{180}$

178 Chris Kabel, What Is the Future of Hospital Community Benefit Programs?, STAN. SOC. INNOVATION REV. (June 2013), http://ssir.org/articles/entry/what_is_the_future_of_hospital_community_benefit_programs.

179 Cf. Supporting Alignment and Accountability in Community Health Improvement, supra note 71 (noting that established community benefit activities may constrain hospital choices in implementing CHNAs).

180 Cf. IRS Hospital Study, supra note 45, at 4 (noting the difficulty of having a more precise standard than community benefit that applies to diverse set of hospitals currently 


\section{B. Four Values To Promote}

\section{Transparency}

Transparency and accountability are cardinal virtues for the IRS to promote in further CHNA guidance to hospitals. Beyond the world of hospitals, these values are of central concern in the broader nonprofit sector. The National Council on Nonprofits advises its constituents on practices for "Cultivating a Culture of Accountability and Transparency." 181 The two values are connected (and are also related to community engagement and collaboration), but addressing each separately permits a more careful teasing out of its distinctive value.

In the context of hospitals' CHNA obligation, transparency entails openness with respect to both the process by which the CHNA report and implementation strategy are created and the end products. This transparency offers benefits on several levels. ${ }^{182}$ A hospital's openness in sharing information about how it assessed its community's health needs and decided on strategies to respond to those needs helps community members understand how they might engage with the hospital's efforts or tap into health improvement resources. Mandating transparency regarding a hospital's response to community health needs may prompt hospitals to devote greater attention and resources to those needs ${ }^{183}$ in order to enhance their reputation in the community and generate greater patient affinity. ${ }^{184}$ Recent research suggests that the transparency associated with targeted disclosure laws may empower hospital staff to carry out their responsibilities more effectively. ${ }^{185}$ In addition, information about hospitals' CHNA processes and conclusions may serve as useful data for health

doing different things).

181 See Financial Transparency, NAT'L COUNCIL NoNPROFITS, http://www.councilofnonprofits.org/tools-resources-categories/financial-transparency (last visited Jan. 4, 2016).

182 Accord Rosenbaum, supra note 24, at 6 (listing the benefits of transparency).

183 See, e.g., Timothy D. Lytton et al., There Is More to Transparency than Meets the Eye: The Impact of Mandatory Disclosure Laws Aimed at Promoting Breastfeeding, 40 AM. J.L. \& MED. 393 (2014) (describing how mandatory disclosure laws designed to increase breastfeeding encouraged nurse managers within hospitals to advocate for changes to hospital policies and implement performance standards).

184 Cf. David Grande et al., Perceived Community Commitment of Hospitals: An Exploratory Analysis of Its Potential Influence on Hospital Choice and Health Care System Distrust, 50 INQUIRY 312 (2013) (reporting results of a survey finding that patients with favorable views of their local hospital's community commitment were more likely to choose the hospital for surgery).

185 See Lytton et al., supra note 183. 
departments engaged in health improvement efforts. ${ }^{186}$

Transparency is also a precondition for a hospital's accountability, whether to regulators or community members. On the most obvious level, the IRS's ability to determine a hospital's compliance with the CHNA requirement depends on receiving sufficient information from the hospital. More broadly, transparency regarding hospitals' community health-oriented activities provides some accountability to the public and the hospital's particular community on how the hospital is actually using the financial benefit it receives from tax exemption. In that sense, requiring greater transparency regarding a hospital's community health-oriented efforts is analogous to the transparency mandated by the Federal Funding Accountability and Transparency Act (FFATA). ${ }^{187}$ That law provides for online information about federal expenditures (e.g., grants, loans, and contracts) so that the public can know how tax dollars are being spent and hold the government accountable for spending decisions. ${ }^{188}$ Because the forgone revenue from hospital tax exemption is akin to a tax expenditure, ${ }^{189}$ similar value lies in the public availability of information about hospital expenditures.

In addition, transparency regarding a hospital's community health assessment and improvement activities facilitates the formation and effective functioning of partnerships. A hospital's openness about its prioritization of community needs and plans to address those needs permits other organizations to

186 For example, the Pennsylvania Department of Health has considered the community health priorities identified by Pennsylvania hospitals in their first round of CHNAs as part of the state health department's identification of health needs. I learned about the Pennsylvania Department of Health's approach from a conversation with faculty members at the University of Pittsburgh's Graduate School of Public Health regarding uses of the data collected in hospital CHNAs.

187 Pub. L. No. 109-282, 120 Stat. 1186 (2006) (codified as amended at 31 U.S.C. $\S$ $6101(2012))$.

188 See About FSRS, Fed. Funding ACCOUnTability \& Transparency ACT SUBAWARD REPORTING SYS., http://www.fsrs.gov (last visited Jan. 4, 2016) ("The intent [of the FFATA] is to empower every American with the ability to hold the government accountable for each spending decision. ... [T] The legislation requires information on federal awards (federal financial assistance and expenditures) be made available to the public via a single, searchable website ....").

189 In recent years, the federal government increasingly has sought to measure the extent and effectiveness of tax expenditures, which it defines as revenue losses resulting from special tax code provisions that reduce taxpayers' income tax liabilities, JOINT COMM. ON TAXATION, JCS-97-14, ESTIMATES OF FEDERAL TAX EXPENDITURES FOR FisCAL YEARS 2014-2018, at 2 (2014). According to the Joint Committee on Taxation, "The tax exemption for charities is not treated as a tax expenditure even if taxable analogues may exist. For example, the tax exemption for hospitals and universities is not treated as a tax expenditure notwithstanding the existence of taxable hospitals and universities." Id. at $9 \mathrm{n}$. 19. Although the revenue forgone as a result of a hospital's tax exemption thus does not meet the federal government's definition of tax expenditure, the value of transparency that supports accountability still pertains. 
identify areas of shared concern, paving the way for possible partnerships. Community health collaborations require open communication among partners to ensure alignment and coordination of efforts, and transparency is particularly vital in multi-sector, sustained collaborations seeking to produce "collective impact" on a complex problem. ${ }^{190}$

Finally, transparency regarding hospitals' experiences as they engage in community health improvement activities-whether those experiences are encouraging or disappointing-lays the foundation for collective learning and the development of best practices. For example, the hospitals and health systems in the Health Systems Learning Group committed to sharing information to permit learning from one another's experiences. ${ }^{191}$ More broadly, the availability of sufficiently granular information regarding hospitals' experiences in implementing the CHNA requirement provides researchers with the data needed for developing process improvements and evaluating the impact of the legislative requirement. $^{192}$

Of course, transparency is not cost free. In the simplest terms, hospitals' collecting, recording, and sharing of information demand resources in the form of staff training and time and technology support. Hospitals' concerns about the level of detailed transparency required were evident in comments on early versions of the IRS CHNA guidance, where hospitals voiced worries about having to identify every community member providing any input during the CHNA process. ${ }^{193}$

Beyond the financial cost, asking hospitals to share information about their CHNA process may uncover reservations relating to reputational or competitive concerns. In the years when hospitals' tax-exempt status was defined only in terms of "community benefit," many hospitals relied on their marketing departments to gather and publicize information about their community benefit

190 John Kania \& Mark Kramer, Collective Impact, Stan. Soc. InNovation Rev., Winter 2011, at 36, 36.

191 See Health Sys. Learning Group Monograph, supra note 126, at 5 .

192 Cf. Kristin Madison et al., Using Reporting Requirements To Improve Employer Wellness Incentives and Their Regulation, 39 J. Health POL. POL'Y \& L. 1013 (2014) (making a similar point with respect to employer wellness programs and proposing reporting requirements); Supporting Alignment and Accountability in Community Health Improvement, supra note 71 , at 88 (noting the value of increased transparency regarding the roles and contributions of various stakeholders as providing "a practical means of disseminating innovative approaches to comprehensive community health improvement").

193 See Community Health Needs Assessments for Charitable Hospitals, 78 Fed. Reg. 20523, 20531 (proposed Apr. 5, 2013) (to be codified at 26 C.F.R. pt. 1) ("[The] CHNA report may summarize, in general terms, how and over what time period input was provided, and need not provide a detailed description of each instance of feedback."). 
activities. ${ }^{194}$ From a business perspective, hospitals' incentive was to craft a community benefits approach that enhanced their image within their community and satisfied the IRS, while minimizing the actual resources deployed. Striking this balance offered a hospital a competitive edge, along with an incentive to treat its community benefit operations as entailing proprietary information, but this view of community benefit is opposed to a high level of transparency.

Although some hospitals have shown a commitment to transparency regarding their CHNA processes, the pilot study of the first round of CHNA reports found transparency lacking in a number of areas. Because of the importance of transparency and countervailing concerns that may lead some hospitals to hang back from sharing information, ongoing guidance by the IRS should promote greater transparency.

The IRS already made an important commitment to transparency by interpreting the ACA's requirement that CHNA reports be "widely available to the public" as requiring the hospital to post its CHNA report online, in addition to making a paper copy available for public inspection at the hospital. ${ }^{195}$ These are steps in the right direction, but making the CHNA report, which describes the assessment process and its results, easily accessible to community members does not fully meet the need for transparency. Information about the hospital's plans and the activities underway to address high priority needs should also be readily available to community stakeholders, potential partners, and researchers.

Currently, the Regulations require a hospital to file annually with the IRS (1) either a copy of its current implementation strategy or a link to the website where it has posted the implementation strategy along with its CHNA report, and (2) a description of its activities during the past year to address the significant health needs identified in its CHNA or an explanation of why no action was taken with respect to one or more needs. ${ }^{196}$ Thus, the IRS already requires hospitals to collect and report this information, and the IRS filings are a matter of public record, although they may not be easily accessible to community members. ${ }^{197}$ To heighten the transparency of hospitals' community health

194 See Community Benefit Contributions and Reporting: Emerging Standards Present an Opportunity for the U.S. Nonprofit Hospital Sector To Articulate Benefits Clearly and with a Unified Voice, CHARTIS GROUP 4 (2009), http://www.chartis.com/files/pdfs/chartiscommunity-benefit-contributions-reporting-health-care-management.pdf; $A$ Marketer's Guide to Community Benefit Reporting and IRS Form 990, PATSY METHENY, LLC, at xvi (2009), healthleadersmedia.com/supplemental/7757_browse.pdf ("The responsibility rests with hospital and health system marketers to put all the pieces of community benefit together to create a consistent, ongoing message that demonstrates the organizations' commitment to improving the community's health status.").

195 Treas. Reg. $§ 1.501($ r)-3(b)(7) (2015).

196 Treas. Reg. § 1.6033-2(a)(2)(ii)(I)(2), (3).

197 See supra note 98 and accompanying text. 
activities and undercut the view that those activities constitute proprietary information, the IRS should require hospitals to post their implementation strategies online alongside their CHNA reports and to provide annual online updates of community health activities underway. Requiring this additional level of transparency should not burden hospitals, who must already collect and report this information to the IRS, and it would go a long towards promoting a continuing flow of communication between hospitals and their communities.

In addition, the IRS should encourage greater transparency by further clarifying its expectations for the processes and standards hospitals should employ when conducting and reporting on their needs assessments and strategies. Initial reviews of the first round of CHNA reports note the challenge of determining how hospitals defined their communities, the nature and extent of input received from community representatives, and the process used for prioritizing significant health needs. ${ }^{198}$ The lack of detail is not surprising. For most hospitals, preparing a CHNA report pursuant to the ACA was their maiden voyage into new and unfamiliar waters, and the IRS's preliminary guidance left open many questions about what hospitals had to do and report. As the process becomes more familiar, the IRS should communicate its expectations that hospitals describe their processes, decisions, rationales, and findings with greater granularity. Sufficient detail is critical not only for demonstrating hospital accountability to local communities and the federal fisc, but also for providing data to enable assessment of whether establishing community health obligations for tax-exempt hospitals contributes to improvements in community health. ${ }^{199}$

\section{Accountability}

In contrast to increasing emphasis on transparency, a stronger commitment to accountability would hold hospitals more clearly responsible for meeting the legal expectations established by the $\mathrm{ACA}^{200}$ and, on some level, for contributing to community health improvement. If transparency is about openness and availability of information, accountability is about holding decision makers answerable for their actions. At the most basic level, accountability would ensure that hospitals benefiting from federal tax exemption in fact do what the law

198 See Supporting Alignment and Accountability in Community Health Improvement, supra note 71, at 85-89; Wade \& Matthews, supra note 169, at 2.

199 Cf. Jessica Berg, Putting the Community Back into the "Community Benefit" Standard, 44 GA. L. REv. 375, 412-15 (2010) (noting difficulty of measuring public health benefits).

200 These include the steps required for compliance with the CHNA requirement, as well as the requirements relating to financial assistance policies, hospital charges, and collection practices. For a discussion of the latter requirements, see supra note 43 and accompanying text. 
directs them to do. More exacting accountability would ask whether an individual hospital's actions measurably improved a health need in its community. Finally, we may also consider the government's accountability: Does imposing a CHNA obligation on hospitals as a condition of tax exemption produce an aggregate public good? Thus, the IRS should consider several levels of accountability.

Accountability requires at a bare minimum some mechanism for ensuring that tax-exempt hospitals have completed the CHNA-related steps required by $\S 501(\mathrm{r})$ and the Regulations. Currently, basic accountability attaches to the requirement that hospitals make their CHNA report available online and Schedule H's inclusion of questions about whether and how a hospital conducted a CHNA and addressed the needs identified. The information requested from hospitals remains fairly minimal, particularly when it comes to carrying out their plans to address a community health need. Schedule $\mathrm{H}$ asks hospitals to indicate how they have addressed needs identified in their CHNAs, but a hospital can respond simply by checking a box for "Execution of the implementation strategy." The instructions direct hospitals to check that box "if the hospital facility has begun, continued, or completed execution of its implementation strategy." This check-the-box approach provides little in the way of transparency and signals little appetite on the IRS's part for holding hospitals accountable.

At the very least, the IRS should ask hospitals for more detailed descriptions of what they are actually doing. In addition to advancing transparency, the anticipation of being required to report on activities in some detail should prompt hospitals to be deliberate in performing and tracking their community health activities. Because the Regulations permit a range of consequences for hospitals that fail to comply with $\S 501(\mathrm{r}){ }^{201}$ the IRS can calibrate its response to those hospitals $^{202}$ and thus may be willing to impose accountability measures.

Another layer of accountability involves trying to determine whether a hospital's community health-oriented activities have an actual impact on the community health needs the hospital seeks to address. One scholar writing about accountability for nonprofit organizations contrasts an organization's accountability "upwards" toward its funders (here, the federal government) with its accountability "downwards" towards groups that use its services or, more

201 The possible consequences range from the revocation of $\S 501(\mathrm{c})(3)$ status for an organization, to the imposition of a $\$ 50,000$ excise tax, to the IRS's ignoring minor omissions and errors that are either inadvertent or due to reasonable cause. If a hospital organization operates multiple hospitals and one of them fails to comply, the income from the noncompliant hospital facility will be subject to taxation. See 26 C.F.R. §1.501(r)-2 (2015); 26 C.F.R. $\$ 53.4959-1$ (2015).

202 See Berg, supra note 199, at 406 (suggesting the possible value of intermediate sanctions). 
broadly, to the communities its programs indirectly affect. ${ }^{203}$ Assessing a hospital's "downwards" accountability by measuring the impact of its community health-oriented activities presents a daunting challenge. ${ }^{204}$ Public health interventions targeting upstream determinants of health are hard to evaluate because of the slow pace at which the root causes of poor health typically change and the difficulty of teasing out the contributions of the various factors affecting health. ${ }^{205}$ Moreover, improving key indicators of population health will typically require shared responsibility among hospitals, public health agencies, and other community organizations, so that no single organization can be held accountable for outcomes. ${ }^{206}$

Even when an intervention targets a discrete health behavior or outcome for improvement, hospitals typically are not well equipped - in terms of either staff expertise or health information and data tracking technologies - to develop and implement metrics and strategies for monitoring progress. ${ }^{207}$ Perhaps most importantly, because hospitals are "learning by doing" as they begin conducting assessments and devising health improvement strategies, it seems unwise at this point to hold them accountable (in the sense of subjecting them to bad consequences) for failing to make measurable progress in improving community health. If anything, hospitals should be encouraged to be ambitious, rather than play it safe, as they consider the impact they might have on their community's health. ${ }^{208}$

Reservations about the feasibility of expecting individual hospitals to rigorously evaluate the impact of their community health activities, however, do not justify abandoning or watering down a commitment to accountability. Peter Drucker's saying- "what gets measured gets managed"-applies here, and points to the importance of requiring hospitals to engage in some form of monitoring and reporting changes in the community health needs they seek to address. ${ }^{209} \mathrm{~A}$ hospital that is part of a collaborative health improvement initiative

203 See Alnoor Ebrahim, The Many Faces of Nonprofit Accountability, in JosSEY-BASS HandBook on NonPRofit Leadership \& MGMT. 101, 103 (David O. Renz ed., 2010).

204 See Rubin et al., supra note 49 , at 614.

205 Cf. Berg, supra note 199, at 413.

206 See Stoto \& Ryan, supra note 104, at 8.

207 Supporting Alignment and Accountability in Community Health Improvement, supra note 71, at 80-81; cf. Jessica G. Burke et al., What Can Be Learned from the Types of Community Benefit Programs That Hospitals Already Have in Place?, 25 J. Health Care POOR \& UNDERSERVED 165, 178 (2014) (finding that few community benefit programs are evaluated rigorously and suggesting that hospitals partner with public health professionals to carry out and evaluate their programs).

208 See Nelson et al., supra note 14, at 9 (cautioning that "an outcome-based approach could raise concerns regarding whether nonprofit hospitals might become risk-averse, perhaps leading to a smaller number of creative, innovative strategies and activities").

$209 C f$. Corrigan et al., supra note 109 , at 1211 (characterizing the regulatory structure as 
could be required to report on its performance of its agreed-on contribution to the collaboration. ${ }^{210}$ In addition, in developing their strategies, hospitals and their partners can rely on a growing body of evidence documenting interventions that produce community health improvements. ${ }^{211}$

The July 2013 proposed regulations would have required hospitals to include a plan for measuring impact as part of their implementation strategy, but they contained no requirement for reporting the results of those measurements. By contrast, the final Regulations no longer require the implementation strategy to include an evaluation plan, but instead call for CHNA reports to include an evaluation of the impact made by the hospital's activities responding to health needs identified in the hospital's preceding CHNA report. Ideally, a hospital's strategy for addressing a community health need should include, from the beginning, an articulation of how the hospital expects its strategy will affect its prioritized health needs and a plan for measuring impact. ${ }^{212}$ Without that, engaging in activities with no reasoned basis for expecting them to have an impact is too easy for hospitals. Imposing the discipline of identifying a basis in evidence or logic for believing that activities will have an impact seems likely to improve the quality of hospitals' strategies, as well as to enhance the chance of actual impact.

Hospitals may object to the imposition of both a front-end requirement of a plan for evaluation and a back-end requirement of reporting evaluation results as more burdensome than the Regulations' more limited approach. Such a requirement should not only enhance the effectiveness of individual hospitals' strategies, but also encourage hospitals to participate in community health collective impact efforts ${ }^{2 / 3}$ and better equip researchers and policy makers to assess whether the CHNA requirement produces measurable community benefit. $^{214}$ Thus, efforts by individual hospitals to monitor, measure, and report

providing hospitals "a substantial amount of flexibility while requiring little accountability or evidence of effect on population health").

210 See Stoto \& Ryan, supra note 104, at 11.

211 See Rosenbaum et al., supra note 108 (citing government and nonprofit reports).

212 Cf. Simone R. Singh, Community Benefit in Exchange for Non-Profit Hospital Tax Exemption: Current Trends and Future Outlook, 39 J. HEAlTH CARE Fin. 32, 39 (2013) (suggesting that "the performance measures that hospitals specify in their improvement plans may serve as the basis for an evaluation of the health outcomes").

213 See Kania \& Kramer, supra note 190, at 40 (noting that one of the five conditions needed for a successful collective impact effort is a shared measurement system for collecting data and measuring results consistently).

214 See Rosenbaum, supra note 24, at 6 ("[I]nnovative promising practices can be coupled with thorough evaluation to help improve health and further build the evidence base for community interventions."). 
the impact of their community health activities are an essential building block for evaluating the impact of the ACA's CHNA requirement.

This point leads to the third dimension of accountability that the IRS should advance in providing guidance to hospitals: the accountability of policy makers to assess whether policies are achieving their desired ends. Over time, researchers-if good data are available-should be able to evaluate whether requiring tax-exempt hospitals to complete the CHNA-related requirements of $\S 501(\mathrm{r})$ leads to improvements in the community health problems targeted, to more efficient collaborative approaches to community health problems, or to whatever policy goal might be assessed. If the CHNA requirement is shown to lead to measurable improvements in the effectiveness or efficiency of community health improvement efforts, then the ACA's innovation may be judged a success. If it is not, then the whole CHNA requirement appears as an empty exercise that imposes burdens on hospitals to no good end. If data about what hospitals do and how health measures change are unavailable or spotty, then we can only scratch our heads and wonder whether the CHNA policy has accomplished anything.

Because most hospitals are beginners when it comes to developing evaluation strategies for community health interventions and tracking data regarding community health measures ${ }^{215}$ the IRS may justify the Regulations' limited approach to accountability by referring to the need to learn to crawl before walking or running. Over time, however, accountability mechanisms should be refined. While an enforcement approach emphasizing efforts over outcomes seems a wise way for the IRS to begin, it should explore ways to maximize the collection and evaluation of data as soon as possible. Developing an evidentiary basis for assessing which community-focused hospital initiatives actually work must be addressed if the goal is truly community health improvement on a large scale.

\section{Community Engagement}

Community engagement is a third value that the IRS should promote in ongoing guidance. A core tenet of public health practice recognizes community engagement as critical to effective community health improvement initiatives. ${ }^{216}$

215 See Barilla et al., supra note 126, at 11 (describing the need for hospitals to develop models for evaluating "the complex interaction of factors that contribute to changes in utilization, improved health outcomes, and improvised conditions in the broader community," which the Report calls "social returns on investment").

216 See generally NAT'L InSts. Health, No. 11-7782, PrinCiples of COMmunity

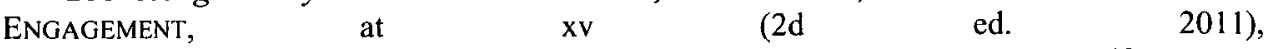
http://www.atsdr.cdc.gov/communityengagement/pdf/PCE_Report_508_FINAL.pdf (providing guidance and tools for community engagement efforts and describing the science base supporting community engagement). 
Community engagement is important both for identifying and understanding a community's health problems and for maximizing the effectiveness of interventions. Therefore, if the CHNA requirement seeks for hospitals to play a meaningful role in improving the health of their communities, closely involving those communities in the process is essential. As discussed above, emphasizing transparency and accountability will facilitate community engagement. As discussed below, this community engagement will enhance a hospital's ability to form effective partnerships.

Ideally, a hospital would continually interact with groups and individuals in its community. ${ }^{217}$ Highlighting two particular points in the community health improvement cycle, though, may be helpful: (1) soliciting and considering community input in identifying and prioritizing health needs, and (2) developing and implementing strategies that involve community members on an ongoing basis. These are both points where the IRS could facilitate or require greater community engagement by hospitals. ${ }^{218}$

To the first point, the Regulations provide that satisfying the statutory requirement of taking into account input from persons representing the broad interests of the community requires hospitals to "solicit and take into account input from "[m]embers of medically underserved, low-income, and minority populations ... or individuals or organizations serving or representing the interests of such populations." ${ }^{219}$ The final Regulations clarify that hospitals should consider community input in both identifying and prioritizing significant health needs, ${ }^{220}$ as well as in identifying resources that might be tapped to address those needs. They also indicate that a hospital can demonstrate its compliance by summarizing the input received, "how and over what time period it was provided," what organizations provided input, and what "medically underserved, low-income, or minority populations" were represented. ${ }^{221}$

Expanding hospitals' obligation to consider community input not only in identifying needs, but also in prioritizing these needs and identifying potentially helpful resources, represents the IRS's validation of community engagement. An examination of the first round of CHNA reports reveals that few hospitals indicated that community members participated in setting priorities. More

217 See Rosenbaum, supra note 24, at 5 ("Successful models indicate that community engagement is essential at each stage of the community health improvement process ....").

218 In addition, the Regulations require that, in conducting CHNAs after their initial one, hospitals must take into account written comments received on its most recent CHNA and implementation strategy. 26 C.F.R $\S 1.501(\mathrm{r})-3(\mathrm{~b})(5)(\mathrm{C})(2015)$.

$219 \S 1.501(\mathrm{r})-3(\mathrm{~b})(5)(\mathrm{B})$.

220 Id. The proposed regulations referred only to hospitals' consideration of input in "assessing health needs." Community Health Needs Assessments for Charitable Hospitals, 78 Fed. Reg. 20,523, 20,541 (proposed Apr. 5, 2013) (to be codified at 26 C.F.R. pt. 1).

22126 C.F.R. $\S 1.501(\mathrm{r})-3(\mathrm{~b})(6)(\mathrm{iii})$. 
generally, researchers could not determine whether hospitals' solicitation of input created meaningful opportunities to engage community members or simply represented the hospitals' jumping through regulatory hoops. ${ }^{222}$ Similarly, these researchers distinguished community consultation from community engagement. ${ }^{223}$ Simply seeking information or opinions from community members and stakeholders, without drawing them into dialogue about their views, experiences, and ideas, will not produce the full benefits of community engagement. Such inquiry without true engagement may help explain why many hospitals used criteria for prioritizing health needs that focused more on the hospital's situation than on the community and its needs. ${ }^{224}$

Hospitals' limited vision of community engagement (likely combined, in many cases, with a desire to control and circumscribe their eventual commitments) likewise affects the strategies hospitals adopt for addressing community needs. One of the few studies to date of the initial round of CHNA reports and implementation strategies found that hospitals' strategies emphasized clinical care initiatives over addressing health behaviors or social, economic or environmental factors. ${ }^{225}$ Carrying out strategies of the latter ilk more likely entails ongoing community engagement, but may be "messier," requiring the hospital to cede some control.

Because the optimal level of community engagement depends on the widely varying situations of both hospitals and their communities, rejecting any prescribed formula for community engagement is appropriate. That said, the IRS should pursue steps to increase hospitals' robust engagement of their communities. Without mandating any particular form of engagement, it could require greater specificity from hospitals in reporting how they solicit and take into account input from community representatives, which groups participated in the CHNA and implementation strategy processes, and how community input translated into priorities and strategies. With that information readily available, community members can see either that their input has an impact on what the hospital does (which could motivate them to become further involved) or that the hospital disregards their input (which could motivate them to demand greater consideration). ${ }^{226}$

Moreover, making more granular information about individual hospitals'

222 Supporting Alignment and Accountability in Community Health Improvement, supra note 71 , at $77-78$.

$223 \mathrm{Id}$. at 84 .

$224 \mathrm{Id}$. at 78.

225 Wade \& Matthews, supra note 169 , at 2.

226 Cf. Supporting Alignment and Accountability in Community Health Improvement, supra note 71 , at 77 (noting that it was unclear from review of CHNA reports how meaningful community engagement was and whether it had any influence). 
interactions with their communities available would permit researchers to draw comparisons among hospitals' performances in terms of community engagement and to describe best practices available to assist hospitals seeking to connect more effectively with their communities. The IRS may not have the resources or inclination to scrutinize closely the seriousness of hospital efforts at community engagement, but researchers do, if only the data were available. Finally, clarifying that community-focused collaborative activities addressing social determinants of health will "count" in satisfying a hospital's community benefit obligation could remove a lingering disincentive for some hospitals to invest in community engagement. Uncertainty on that point may make hospitals reluctant to move beyond more conventional community benefit activities. ${ }^{227}$

\section{Collaboration: Where It All Comes Together}

Several aspects of the Regulations lay the foundation for hospitals' collaboration with one another and other community stakeholders during the process of assessing and addressing community health needs. By requiring hospitals to solicit and take into account input from health departments and members or representatives of minority, underserved and low-income groups, the Regulations require some level of dialogue, an obvious precondition to collaboration. They also reinforce the centrality of a population health perspective. In addition, the Regulations not only endorse partnering in assessment processes and sharing information, they also permit some hospitals to submit joint CHNA reports and implementation strategies, as long as hospitals do not use "collaboration" as a mask for free-riding on others' efforts and commitments.

Going forward, the IRS should recognize factors that may make collaboration attractive to hospitals, as well as concerns that may undercut collaborative efforts. Its ongoing guidance to hospitals should seek to reinforce the former and counteract the latter. Leaders in the hospital industry recognize partnerships as an essential element of hospitals' playing meaningful roles in improving population health, ${ }^{228}$ as do public health scholars. ${ }^{229}$ By being attuned to forces at play in hospitals' world, the IRS can encourage hospital participation in collaborative projects to improve community health-including broad collective impact initiatives - without mandating any particular collaboration.

The Regulations require hospitals to seek and take into account health department input. The PHI Report, however, found that many hospital CHNA reports left unclear the level and form of engagement that actually occurred

227 See id.

228 See Managing Population Health, supra note 141, at 3-5.

229 See Rosenbaum, supra note 24 , at 3. 
between the hospital and health department and suggested that many hospitals simply may have relied on the health department for help with a particular element of the assessment (for example, providing data or conducting a focus group). Beyond this minimal cooperation, the PHI Report stresses the value of actual alignment between the community health activities of hospitals and health departments, so that limited resources can be leveraged and used efficiently. The IRS can encourage closer hospital/health department collaborations without mandating them by, for example, providing more guidance on what the "take into account input received" requirement actually means. ${ }^{230}$ Ideally, that guidance would identify both the minimum level of consultation that is expected and exemplary practices that are encouraged. Given obstacles to alignment of hospital and health department efforts, joint efforts may not occur immediately. But by clarifying its expectations regarding input, the IRS could make sustained dialogue regarding community needs more likely and thus pave the way for alignment. ${ }^{231}$

Collaborating with other hospitals and health departments may be of particular value. For one, multi-hospital/health department collaborations can defuse the concern that local health departments may not have the capacity to provide the mandated input to numerous local hospitals conducting CHNAs separately and simultaneously. ${ }^{232}$ In addition, working with a health department and other hospitals to devise and carry out community health improvement strategies could be attractive for hospitals new to the CHNA process. However, several practical factors may make it less likely that hospitals will participate in collaborative projects without clearer regulatory encouragement.

First, as discussed above, historically some hospitals have viewed aspects of their community benefit programs as proprietary information. A competitive mindset and unwillingness to share information would prevent effective collaboration among hospitals. While hospitals do not compete with health departments, a general reticence to share information deemed proprietary diminishes the likelihood hospitals will participate in a joint strategy for addressing community health needs. From this perspective, the importance of transparency as a means of undercutting a view of community benefits approaches as proprietary information becomes evident.

The Regulations' relative weakness on accountability may also lower the

$230 \mathrm{Cf}$. Supporting Alignment and Accountability in Community Health Improvement, supra note 71 , at 77 (noting difficulty in determining exactly how a hospital took community input into account and whether opportunities for input were meaningful).

$231 \mathrm{Cf}$. id. at 81-82 (noting obstacles to alignment, but stating: "Where dialogue has been established, there is a growing recognition of the overlap between roles and target populations, and the opportunities to leverage limited resources.").

232 See supra note 133 and accompanying text. 
chances of robust collaborations. As discussed above, the Regulations require a hospital to describe the anticipated impact of its planned actions, report annually on actions taken to address significant health needs, and include in its next CHNA report an evaluation of those actions' impact. These requirements create some accountability for hospitals, but not enough to maximize opportunities for real changes in community health. Recalling the historical lack of clear IRS guidance on what the community benefit standard demands, hospitals may read the absence of guidance on monitoring and measuring impacts as a signal that simply "going through the motions" of evaluating impact will suffice. That approach would be antithetical to public health's growing commitment to evidence-based measurement of impact and could be a barrier to effective partnerships with health departments.

A lack of regulatory enthusiasm for hospitals' collection and sharing of data and measuring impact may be particularly problematic when it comes to encouraging some hospitals to "think big" and be willing to participate in multisector collective impact initiatives to address community health issues. ${ }^{233}$ The AHA Reports identify physicians, payers, employers, social services providers, and community organizations ${ }^{234}$ as having potential roles to play in improving community health, particularly when the target for improvement is a social determinant of health. For hospitals to play a meaningful role in addressing nonmedical factors contributing to poor health, they almost certainly will need to collaborate with other stakeholders. Encouraging hospitals to participate in ambitious health-oriented collective impact initiatives, however, requires adjustment of an additional aspect of the IRS's existing guidance.

Specifically, the IRS should revise its instructions to hospitals completing Schedule $\mathrm{H}$ to clarify that it will deem a hospital's participation in a community health-oriented collaboration to be a community benefit. Because the ACA's creation of the CHNA requirement supplements, rather than replaces, the preexisting community benefit standard, it is theoretically possible that a hospital could satisfy the CHNA requirement but not the community benefit standard. Moreover, while the final Regulations' broad definition of "community health need" should reassure hospitals that the category includes social determinants of health, Schedule H's instructions are less clear that "community building activities" count as community benefit. ${ }^{235}$ This lack of clarity may sap a

233 See Kania \& Kramer, supra note 190, at 40 (identifying a shared measurement system by which participants collect data and measure results consistently using a short list of indicators as one of the five conditions needed for a successful collective impact effort).

234 See Managing Population Health, supra note 141, at 3 fig. 1.

235 As discussed above, recent revisions to those instructions state that some community building activities "may also meet the definition of community benefit," without clarifying which community building activities will meet that definition. See supra Section II.E.2. 
hospital's enthusiasm for participating in a collective impact initiative where the hospital's contribution would not be a traditional form of community benefit. By clarifying that community benefit encompasses efforts to address a social determinant the hospital has identified as a community health need, even if the hospital is not the leader of the partnership, ${ }^{236}$ the IRS could eliminate legal concerns for hospitals willing to think broadly about their roles in their communities. $^{237}$

Going forward, the IRS should provide guidance on these points in order to facilitate and encourage hospitals' partnering with health departments ${ }^{238}$ and other community stakeholders, whether in discrete interventions or in broadreaching collective impact collaboratives. Despite the clear value of hospitals' joining with others to address community health needs, ${ }^{239}$ it would be unwise for

Community building activities are generally understood as strengthening a community's capacity to promote its residents' well being, but the Catholic Health Association has recommended that hospitals use public health literature to demonstrate how a particular community building activity in fact improves the health of individuals and populations in the hospital's community, so that it should count as a community benefit. See Community Benefit and Community Building, CATHOLIC HEALTH Ass'N (2013) (on file with author).

236 See Martha Hostetter \& Sarah Klein, Improving Population Health Through Communitywide Partnerships, QuALITY MATTERS (2012), http://www.commonwealthfund.org/publications/newsletters/quality-matters/2012/februarymarch/in-focus (noting that community-wide partnerships that do not rely primarily on hospital leadership may be more effective and sustainable).

237 The IRS could remedy this situation either by treating all community building activities as forms of community benefit or by clarifying that any community building activities that address a significant health need identified in a hospital's CHNA report can be counted as community benefit. See Supporting Alignment and Accountability in Community Health Improvement, supra note 71 , at 75 (suggesting that the IRS eliminate Part II of Schedule $\mathrm{H}$ as a separate part of the form and fully integrate the community building category into Part I, where hospitals report community benefit expenditures).

238 Another unanswered question regarding the viability of hospital-health department collaborations in conducting assessments lies in the conflicting timelines that the ACA establishes for hospitals and the Public Health Accreditation Board (PHAB) has created for health departments. See Standards \& Measures Version 1.5, PUB. HEALTH ACCREDITATION BD. 13 (2013), http://www.phaboard.org/wp-content/uploads/SM-Version-1.5-Board-adoptedFINAL-01-24-2014.docx.pdf (noting that Standard 1.1 requires health departments to "participate in or lead a collaborative process resulting in a comprehensive community health assessment" at least every five years). Because the three-year CHNA cycle originates in the statute itself, the IRS has no ability to substitute a different time frame, but dialogue between the federal government and the PHAB over possible approaches to coordination could produce a solution.

239 Hospitals themselves recognize this. See, e.g., Role of Small and Rural Hospitals, supra note 141, at 10 (recommending that small and rural hospitals perform their CHNAs in conjunction with their local health departments). 
the IRS to go further and require that hospitals either engage in particular types of partnerships or attempt to address social determinants of health, at least for now. The broad diversity in hospitals' resources, community needs, and potential partners counsels the importance of simultaneously facilitating partnerships, while maintaining significant hospital flexibility. In addition, implementing the previously suggested measures relating to transparency, accountability, and community engagement should help pave the way for successful partnerships. Finally, the IRS can help hospitals learn about the importance of social determinants to community health and the emerging literature regarding best practices for CHNAs and models for collaboration, either by incorporating them in its own guidance or by directing hospitals to the growing resources provided by the nonprofit world and other government departments. ${ }^{240}$

\section{From What to How}

This Article urges the IRS to promote the values of transparency, accountability, community engagement, and collaboration in implementing the CHNA requirement for hospitals. Just how the IRS might go about promoting these values is a necessary correlate of the "what?" question that occupies the previous section. Fully exploring the "how" question is beyond the scope of this Article, but this section highlights several potentially useful ideas other scholars have advanced. These range from proposals that the IRS use its traditional tools for providing guidance to suggestions that it partner with other agencies to draw upon their expertise and resources.

Now that the IRS has finally completed a multi-year process of notice-andcomment rulemaking, it seems unlikely that it would be eager to plunge once again into the rule-making fray. ${ }^{241}$ That said, the agency has many other tools it regularly uses for providing guidance, including revenue rulings, private letter rulings, and technical advice memoranda. ${ }^{242}$ Although these informal means of guidance do not carry the force of law, they are nonetheless official mechanisms

240 Cf. Supporting Alignment and Accountability in Community Health Improvement, supra note 71, at 79-80 (noting the importance of hospital education).

241 One way for pursuing further rulemaking without going through the full notice-andcomment process would be for the IRS to engage in negotiated rulemaking. See Ehren K. Wade, Comment, Just What the Doctor Ordered?: Health Care Reform, the IRS, and Negotiated Rulemaking, 66 ADMIN. L. REV. 199, 231 (2014) (suggesting the use of negotiated rulemaking by the IRS in developing regulations implementing $\S 501(\mathrm{r})$ ).

242 See generally Donald L. Korb, The Four R's Revisited: Regulations, Rulings, Reliance, and Retroactivity in the 21st Century: A View from Within, 46 DUQ. L. REv. 323, 324 (2008) (describing the kinds of guidance the Internal Revenue Service issues to the public and explaining the reliance the public can place on each type of guidance). 
for communicating agency interpretations of the law and agency enforcement approaches. Indeed, the community benefit standard originated in a revenue ruling. ${ }^{243}$

A straightforward way for the IRS to implement at least some of this Article's suggestions would be by revising Schedule H. Revisions might change the information hospitals are asked to supply, thereby advancing transparency and accountability. For example, some commentators have suggested that the IRS revise Schedule $\mathrm{H}$ to require a detailed report from hospitals on the population health outcomes of their activities. ${ }^{244}$ Alternatively, the IRS could more directly promote changes in hospitals' conduct-for example, encouraging sustained community engagement and collaboration-by changing how Schedule $\mathrm{H}$ categorizes certain types of activities. Specifically, the IRS should eliminate the ambiguity in its message about when hospitals' participation in "community building" activities will qualify as community benefits. It could do so broadly, perhaps by instructing hospitals that any community building activities undertaken as part of an implementation strategy responding to an identified community health need will count as community benefit. Or, as suggested by Professor Sara Rosenbaum, the agency could describe "certain evidence-based [community] investments" as falling with a "safe harbor" that will automatically qualify as community benefit expenditures. ${ }^{245}$

Of course, any refinements to the IRS's guidance to hospitals to encourage participation in collaborative efforts addressing determinants of health should be informed by expertise as to the types of engagement and collaboration likely to produce community health improvement. The IRS could adapt its staffing and organizational structure to house such expertise internally, ${ }^{246}$ but that approach seems improbable given the agency's shrinking budget. Alternatively, the IRS could consult or partner with other agencies having substantive expertise in public health, ${ }^{247}$ much as it sought input from the Centers for Disease Control in developing the existing Regulations.

Piggybacking is another possible approach to leveraging expertise from a sister agency, specifically the Centers for Medicare and Medicaid Services (CMS), and encouraging the collection of data for evaluation and accountability purposes. As the federal government seeks new approaches to promoting health, containing costs, and improving quality, CMS is the ringmaster for much innovation, and it increasingly emphasizes public health approaches. One of the

243 Rev. Rul. 69-545, 1969-2 C.B. 117.

244 Rubin et al., supra note 49, at 614.

245 Rosenbaum et al., supra note 108.

$246 C f$. Tahk, supra note 175, at 841-42 (suggesting modification of IRS structure to take into account its growing level of responsibility for anti-poverty programs).

247 Id. at 841. 
goals of CMS's 2013 Quality Strategy was "Prevention and Public Health."248 Describing its role as the driver and enabler of change in these areas, CMS supports change by healthcare providers like hospitals in diverse ways, from establishing the parameters for new risk-based provider collaborations like accountable care organizations (ACOs) to supporting demonstration projects through the Centers for Medicare and Medicaid Innovation. Building on the concept of safe harbors, the IRS could facilitate hospitals' engagement in collaborative initiatives that are somehow under CMS's auspices by assuring hospitals that such participation will count towards their community benefit obligation. $^{249}$ CMS has committed to supporting provider learning and to "improving the use of data for monitoring and continuous improvement ... by aligning population health programs and metrics."250 Blessing hospitals' participation in CMS projects could enhance accountability and make sure that hospitals' activities would feed into a critically important learning loop. It would also promote alignment between CMS's population-health focused efforts and hospitals' compliance activities.

The mechanisms by which the IRS might further refine its guidance to hospitals complying with the CHNA requirement to encourage meaningful contribution to community health improvement merit further exploration. Piggybacking on CMS initiatives seems a particularly promising route, but others doubtless exist as well. The key will be to identify ways to push hospitals towards greater transparency, accountability, community engagement, and collaboration, while eschewing a one-size-fits-all approach that ignores hospital diversity and unduly limits flexibility.

\section{CONCLUSION}

The IRS has issued regulations instructing hospitals how to satisfy the ACA's CHNA requirement for tax exemption, but hospitals remain on a steep learning curve as they adjust to this new expectation. This learning must occur while hospitals also face challenges in adapting to evolving reimbursement methods and competitive landscapes. All the while, a growing chorus of voices proclaims that improving health outcomes in the U.S. while controlling costs

\footnotetext{
248 Ctrs. for Medicare \& Medicaid Servs., CMS Quality Strategy 2013-Beyond, U.S. DEP'T HEALTH \& HUM. SERVS. 1 http://www.ahrq.gov/workingforquality/agencyplans/cms-quality-strategy.pdf.

249 See Corrigan et al., supra note 109 (suggesting that CMMI demonstration projects should encourage hospitals to participate in region-wide CHNAs); Shortell, supra note 16, at 1122 (suggesting that CMS offer "a risk-adjusted community population-wide health budget to local consortia of health care, public health, and community and social service organizations").
}

250 Ctrs. for Medicare \& Medicaid Servs., supra note 248, at 18. 
demands greater integration of public health and healthcare delivery. These circumstances present an opportunity for the IRS to facilitate hospitals' development of CHNA-related approaches that hold real promise for contributing to community health improvement. The IRS has an important role to play in "moving the needle" in community health by focusing its ongoing CHNA guidance to hospitals in order to promote transparency, accountability, community engagement, and collaboration. In the long run, encouraging hospitals to develop a more expansive vision of their role and equipping them to make meaningful contributions to improving the health of their communities may be the greatest "community benefit" of all. 